\title{
Injection Drug Use Among West Virginia Medicaid Beneficiaries: An Analysis of Health Outcomes, Service Utilization, and Cost
}

\author{
Michael J. Cima
}

Follow this and additional works at: https://researchrepository.wvu.edu/etd

\section{Recommended Citation}

Cima, Michael J., "Injection Drug Use Among West Virginia Medicaid Beneficiaries: An Analysis of Health Outcomes, Service Utilization, and Cost" (2017). Graduate Theses, Dissertations, and Problem Reports. 5369.

https://researchrepository.wvu.edu/etd/5369

This Dissertation is protected by copyright and/or related rights. It has been brought to you by the The Research Repository @ WVU with permission from the rights-holder(s). You are free to use this Dissertation in any way that is permitted by the copyright and related rights legislation that applies to your use. For other uses you must obtain permission from the rights-holder(s) directly, unless additional rights are indicated by a Creative Commons license in the record and/ or on the work itself. This Dissertation has been accepted for inclusion in WVU Graduate Theses, Dissertations, and Problem Reports collection by an authorized administrator of The Research Repository @ WVU.

For more information, please contact researchrepository@mail.wvu.edu. 
INJECTION DRUG USE AMONG WEST VIRGINIA MEDICAID

BENEFICIARIES: AN ANALYSIS OF HEALTH OUTCOMES, SERVICE

UTILIZATION, AND COST.

\author{
Michael J. Cima \\ Dissertation submitted to the School of Public Health \\ at West Virginia University \\ in partial fulfillment of the requirements \\ for the degree of \\ Doctor of Philosophy \\ in \\ Epidemiology
}

R. David Parker, PhD, Chair

Michael Brumage, MD, FACS

Sijin Wen, PhD

Tony Atkins

Department of Epidemiology

Morgantown, West Virginia

2017

Keywords: Injection drug use, Service utilization, Cost, Medicaid, Infectious disease

Copyright 2017 Michael J. Cima 


\title{
Abstract \\ INJECTION DRUG USE AMONG WEST VIRGINIA MEDICAID BENEFICIARIES: AN ANALYSIS OF HEALTH OUTCOMES, SERVICE UTILIZATION, AND COST
}

\author{
Michael J. Cima
}

In the United States, injection drug use is a serious public health concern associated with an array of negative health outcomes and substantial financial consequences for systems of care. The purpose of this study was to characterize a statewide sample of Medicaid insured persons who inject drugs in terms of health outcomes, service utilization and cost. A cross-sectional, retrospective analysis of West Virginia Medicaid claims data between 2014 and 2016 was conducted. Between 2014 and 2016, 5,082 West Virginia Medicaid beneficiaries amassed 14,414 service visits, among which inpatient, emergency room, and mental health and substance abuse were the most common. Drug poisonings $(n=5,077)$, soft-tissue infections $(n=4,127)$ and other infectious diseases $(n=2,141)$ were the most common clinical conditions within this sample. Medicaid claims data were not a suitable proxy for state surveillance data as it pertains to new cases of Hepatitis B, Hepatitis C, HIV and heroin overdoses. Ordinal logistic regression results indicate that infectious diseases like endocarditis and soft-tissue infections are associated with increased service utilization. Similarly, multiple regression models show increased cost among individuals with HIV, endocarditis, and Hepatitis B. Preventative services, e.g. syringe exchange programs, are important tools to reducing the spread of infectious diseases, and thereby decrease frequent service utilization and cost among injection drug users. 


\section{DEDICATION}

To my parents, Karl and Cathy, for their unwavering love and support that have propelled me forward my entire life.

To my brother, Dom, for being my best friend and keeping me laughing.

To all the Cima's and Gavin's here and gone, I miss and love you all.

To my friends for the memories and good times to come.

To my beautiful, thoughtful, patient, and inspiring fiancée (by the time this gets published), Laura, who stole my heart on a Miami beach and has brought me nothing but love, happiness, and fulfillment since. 


\section{ACKNOWLEDGMENTS}

My adviser, boss, mentor, committee chair, confidant, and friend David Parker, without whom these past four years would not be nearly as fun nor memorable. Thank you for being you, for challenging me, for believing in me, and for making my success your success.

Michael Regier for his support not only on this project but everything else over these past few years. Thank you for being a great teacher and friend.

My committee, Michael Brumage, Sijin Wen, and Tony Atkins, for their genuine interest and guidance throughout this project. 


\section{TABLE OF CONTENTS}

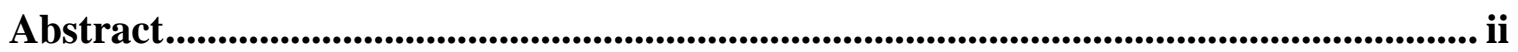

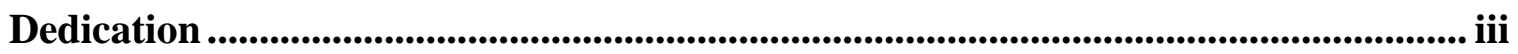

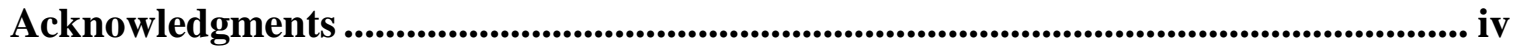

Table of Contents ...................................................................................................................................v

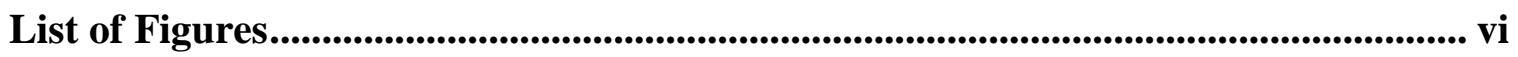

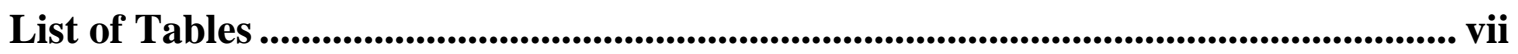

List of Symbols/Nomenclature............................................................................. viii

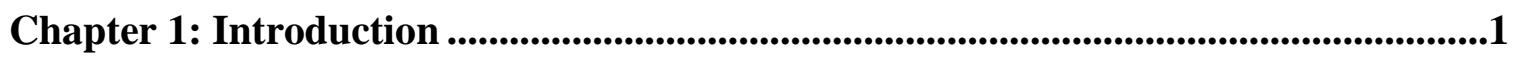

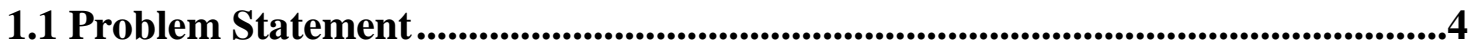

1.2 Conceptual Framework for the Study ....................................................................4

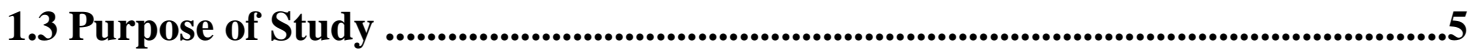

1.4 Specific Aims and Objectives .....................................................................6

1.5 Procedures..............................................................................................................................7

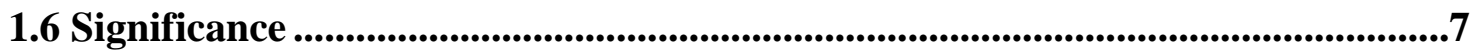

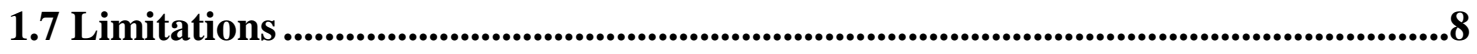

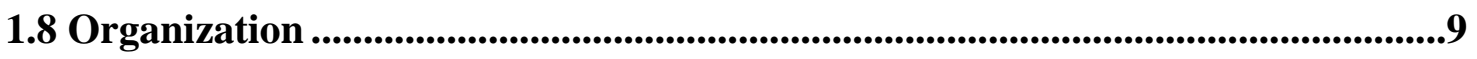

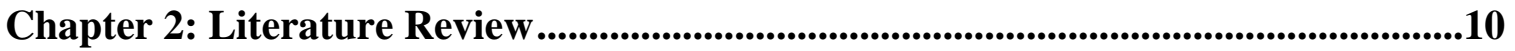

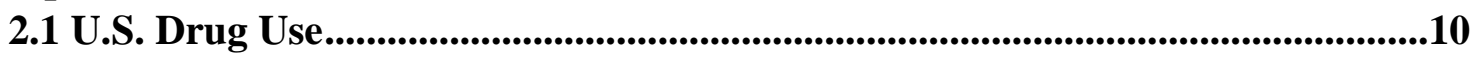

2.2 U.S. IDU ..........................................................................................................................11

2.2.1 Associated Social and Economic Factors ..................................................... 11

2.2.2 Associated Commorbidities......................................................................... 12

2.2.3 Care Access, Utilization, and Economic Impact of IDU ................................13

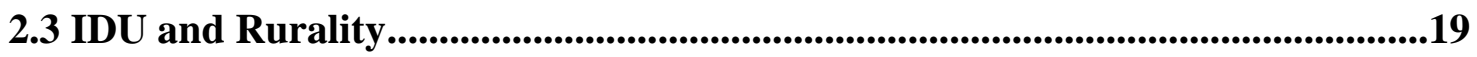

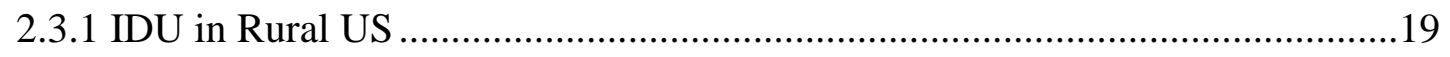

2.3.2 Social and Economic Factors in Rural US ...................................................20

2.3.3 IDU Associated Infectious Diseases: Rural v. Urban .....................................20

2.3.4 Care Access: Rural v. Urban .......................................................................21

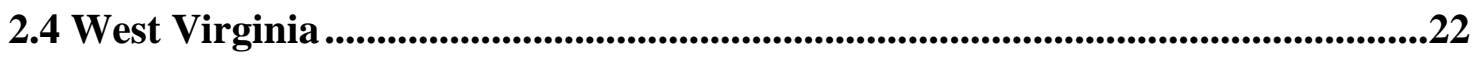

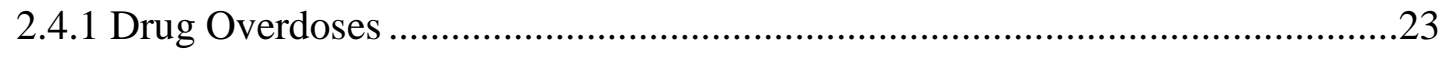

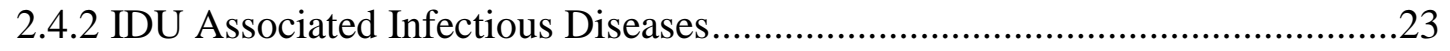

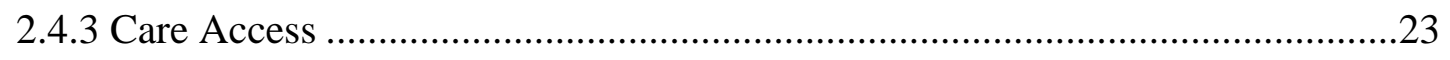

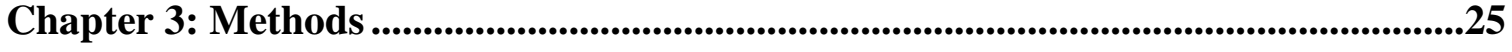

3.1 Participants ..................................................................................................................25 


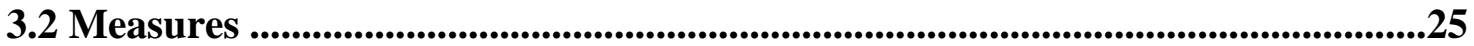

3.3 Design .........................................................................................................................29

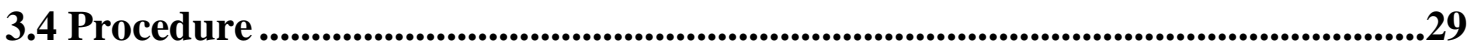

3.5 Outcomes..............................................................................................................................29

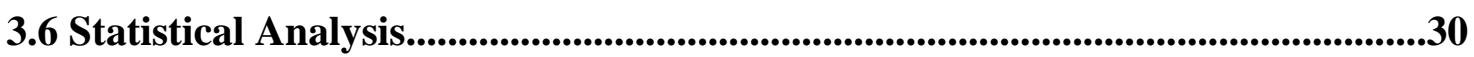

3.6.1 Analyses for Specific Aim 1 …………..................................................31

3.6.2 Analyses for Specific Aim 2 ……………….............................................32

3.6.3 Analyses for Specific Aim 3 ....................................................................33

Chapter 4: Results..................................................................................................................34

4.1 Description of Sample ..................................................................................................................34

4.2 Specific Aim Results..............................................................................................................38

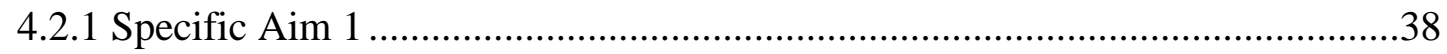

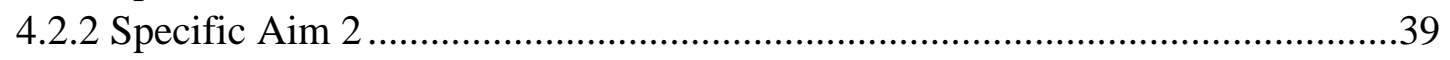

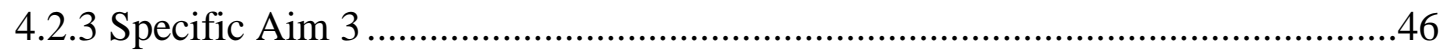

Chapter 5: Discussion .................................................................................................................50

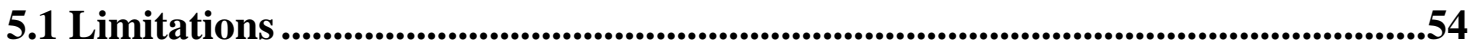

5.2 Future Research ......................................................................................................................55

References...............................................................................................................................................57 


\section{LIST OF FIGURES}

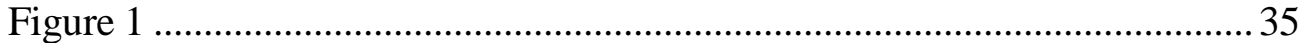

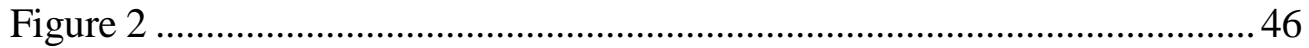




\section{LIST OF TABLES}

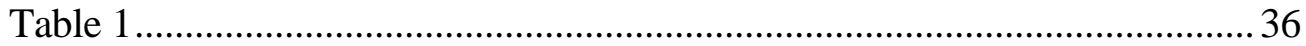

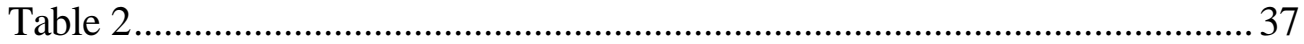

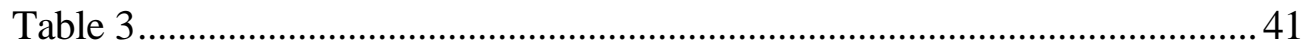

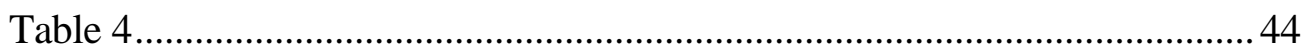

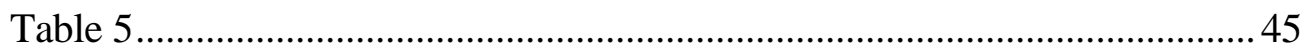

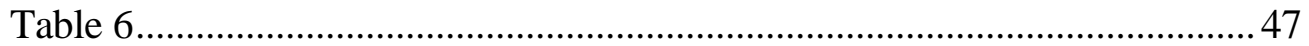

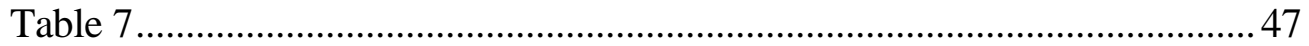

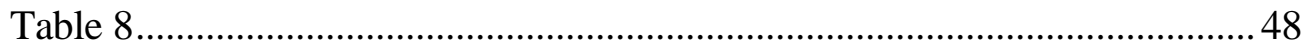

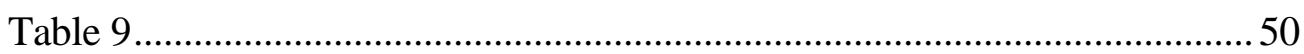

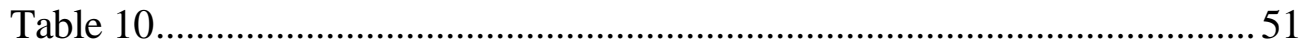

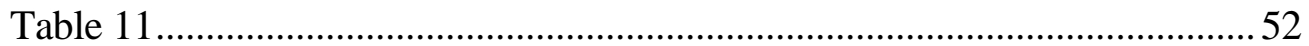

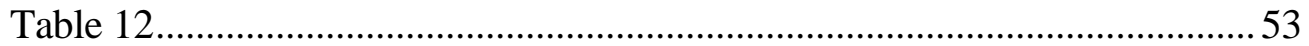

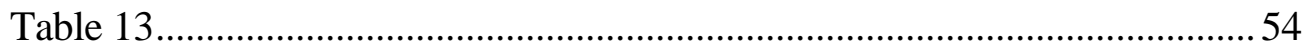

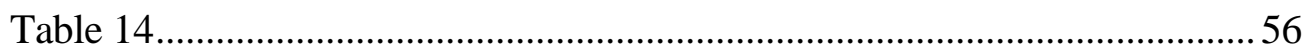

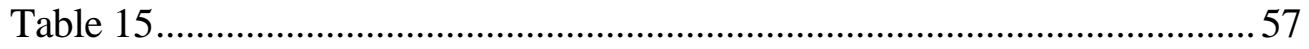

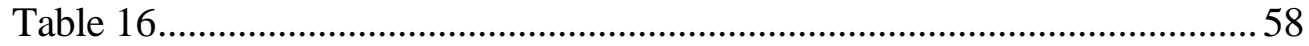




\section{LIST OF SYMBOLS / NOMENCLATURE}

1. ACA-Affordable Care Act, 2010

2. ARC-Appalachian Regional Commission

3. BMS- Bureau for Medical Services

4. DHHR- Department of Health and Human Resources

5. FPL- Federal poverty line

6. HBV-Hepatitis B virus

7. $\mathrm{HCV}$ - Hepatitis $\mathrm{C}$ virus

8. HIV- Human immunodeficiency virus

9. ICD-9- International Statistical Classification of Diseases, Revision 9

10. IDU- Injection drug use

11. OD- Overdose

12. ODD- Overdose death

13. PWID- Person(s) who inject drugs

14. SEP-Syringe exchange program

15. STI- Sexually transmitted infection

16. US- United States

17. WV- West Virginia 


\section{CHAPTER 1: INTRODUCTION}

Persons who inject drugs (PWID) are subject to a myriad of adverse health outcomes, including overdose, withdrawal, viral hepatitis, human immunodeficiency virus (HIV), endocarditis, and other soft tissue infections. (Alter \& Moyer, 1998; Binswanger, Kral, Bluthenthal, Rybold, \& Edlin, 2000; CDC, 2016; Rudd, Seth, David, \& Scholl, 2016) Recent nationwide increases in opioid overdoses, acute hepatitis $\mathrm{C}$ viral infection (HCV), and an HIV outbreak among PWID emphasize the urgency of the injection drug use (IDU) epidemic in the United States (US). (Conrad, Bradley, Broz, Buddha, Chapman, Galang, Hillman, Hon, Hoover, Patel, Perez, Peters, Pontones, Roseberry, Sandoval, Shields, Walthall, Waterhouse, Weidle, Wu, \& Duwve, 2015; Rudd, Aleshire, Zibbell, \& Gladden, 2016; Zibbell, Iqbal, Patel, Suryaprasad, Sanders, Moore-Moravian, Serrecchia, Blankenship, Ward, \& Holtzman, 2015) Between 2002 and 2013, the United States heroin overdose death rate more than tripled, from 0.7 to 2.7 per 100,000 people. (Rudd, Seth, et al., 2016) Concurrently, the leading infectious disease killer in HCV infection increased throughout the US, with the most notable increases occurring among PWID in rural states including Kentucky and West Virginia (WV) located in central Appalachia. (Ly, Hughes, Jiles, \& Holmberg, 2016; Zibbell, Iqbal, Patel, Suryaprasad, Sanders, MooreMoravian, Serrecchia, Blankenship, Ward, \& Holtzman, 2015) In 2015, the Indiana State Department of Health reported a 181 case outbreak of HIV in a rural community where the sharing of injection equipment was a contributing factor in $92 \%$ of reported cases resulting in 92\% of persons coinfected with HCV. (Peters et al., 2016) Additionally, invasive bacterial infections like endocarditis and other soft tissue infections resulting from direct injection into the skin or muscle continue to be one of the most common recurring problems among PWID, and is 
costly to healthcare institutions and insurers. (Binswanger et al., 2000; Fleischauer, Ruhl, Rhea, \& Barnes, 2017; Tookes, Diaz, Li, Khalid, \& Doblecki-Lewis, 2015)

While adverse health outcomes related to IDU have increased throughout the US, studies indicate nonurban and rural areas have been disproportionately impacted over the past ten years. (Des Jarlais et al., 2015; Suryaprasad et al., 2014; Zibbell, Iqbal, Patel, Suryaprasad, Sanders, Moore-Moravian, Serrecchia, Blankenship, Ward, \& Holtzman, 2015) Rural Appalachia, in particular, has experienced the most pronounced increases in HCV, HIV, and overdoses among PWID. A recent study, ranking US counties in terms of vulnerability to the spread of IDU related HCV and HIV identified the most vulnerable counties were largely rural and in the Appalachian region. (Van Handel et al., 2016) Highly effective and cost containing public health interventions to counter IDU associated events have been identified in both rural and urban areas of the world, including syringe and injection equipment exchange programs (SEP). (Kwon, Iversen, Maher, Law, \& Wilson, 2009; D. Wilson, Taaffe, Fraser-Hurt, \& Gorgens, 2014; D. P. Wilson, Donald, Shattock, Wilson, \& Fraser-Hurt, 2015)

SEPs reduce IDU health risks via a harm reduction approach, without the explicit primary objective of IDU cessation. (Bastos \& Strathdee, 2000; Kwon et al., 2009; Vickerman et al., 2006; D. P. Wilson et al., 2015) Nonetheless, multiple studies identified decreasing incidence of HIV and HCV in locations with SEP and increases in locations without SEPs. (D. P. Wilson et al., 2015) SEPs offer a range of services which may include education, counseling, STI testing, distribution of condoms, legal services, and opioid substitution treatment. Some of these services, e.g. peer based education interventions, are also effective in reducing IDU risk behaviors, such as sharing injection equipment. (Mackesy-Amiti et al., 2013)Compared to other prevention strategies, SEPs are relatively inexpensive to implement and sustain, with an 
estimated cost ranging between $\$ 23-\$ 71$ (US) per person, per visit depending on location and services offered with the return on investment of approximately $\$ 5$ saved to every $\$ 1$ spent. (Kwon et al., 2009; D. Wilson et al., 2014; D. P. Wilson et al., 2015)This return on investment was based on the dollars saved for preventing at least one infection such as HIV, HCV, and/or other soft tissue infections compared to dollars spent on equipment and services.

While SEPs are demonstrably effective, these services have not diffused widely in the US, either rural or urban. According to the results of a recent, nationwide study of SEPs from various regions of the US, fewer SEPs were located in rural (30 SEPs) areas compared to urban (105 SEPs) areas. (Des Jarlais et al., 2015) Further, half of rural SEPs were categorized as "small" or "medium", and exchanged far fewer syringes per program than their urban counterparts (medians of 55,000 syringes exchanged vs. 146,263 syringes exchanged) In terms of operating characteristics, rural SEPs report fewer mobile exchanges, more problems with procuring funding, reaching participants, and fewer full-time personnel. (Des Jarlais et al., 2015) Additionally, the federal ban on funding components of SEPs persists ("Public Health and Welfare Act," 1988), thus potentially limiting the availability of services and resources. The lack of prevention services for PWID in rural areas is an important disparity which not only directly affects public health, but also increases the amount of money spent on healthcare by insurers, including Medicaid.

There is an established link between IDU and poverty in wealthy countries. (Crime, 2016) With the expansion of Medicaid, a government subsidized health insurance program, under the Affordable Care Act (ACA) in 2010, health insurance is more available to millions of lower income Americans, decreasing uninsured adults. (Blumenthal, Abrams, \& Nuzum, 2015) In states with expanded coverage, individuals with a household income at or below $133 \%$ of the 
federal poverty level (FPL) are eligible for Medicaid. (Blumenthal et al., 2015) Therefore, Medicaid expansion may result in more PWID receiving coverage. Even prior to Medicaid expansion, studies have shown that PWID are often covered by Medicaid when eligible.

(Fleischauer et al., 2017; Takahashi, Baernstein, Binswanger, Bradley, \& Merrill, 2007; Tookes et al., 2015) In these studies, Medicaid was billed for a majority of the injection drug-related services rendered, and these services tended to be more expensive than services for other patients during the same time. One study estimated the average cost per hospitalization for PWID with soft-tissue infections, like abscesses and cellulitis, was $\$ 4,449$ compared to $\$ 3,540$ for non-IDU related hospitalizations (US). (Takahashi, Maciejewski, \& Bradley, 2010) In another similar study, costs of treating endocarditis among PWID exceed \$50,000, and were billed to Medicaid for $42 \%$ of the time. (Fleischauer et al., 2017)

\subsection{Problem Statement}

Emergency and other care costs for persons who inject drugs are increasingly covered by Medicaid expansion and other publicly funded programs. (Tookes et al., 2015) Few studies have utilized individual level Medicaid data from a rural state to assess care costs and utilization. Use of Medicaid claims data may provide a unique opportunity to address gaps in knowledge surrounding service utilization and associated costs within this hard to reach population.

\subsection{Conceptual Framework for the Study}

Several studies use claims data to investigate various issues related to drug abuse. (Birnbaum et al., 2011; Dufour et al., 2014; McAdam-Marx, Roland, Cleveland, \& Oderda, 2010; Shei et al., 2015; White et al., 2005) The methodology of a majority of these studies involves retrospectively querying claims databases, using ICD-9 \& ICD-10 codes, in order to 
describe the prevalence and cost of opioid drug abuse among an insured population. As of October 1, 2015, the United States shifted from ICD-9 to ICD-10 codes. (CDC, 2017) Studies querying claims databases with ICD codes generally show that the prevalence of opioid abuse has increased, (Dufour et al., 2014) opioid abusers tend to have more comorbidities, (McAdamMarx et al., 2010; Shei et al., 2015) and costs associated with opioid abuse are significant. (McAdam-Marx et al., 2010; White et al., 2005) However, the current body of research surrounding claims data and drug abuse focuses predominantly on prescription opioid abuse, perpetuating the gap in IDU, which is further exacerbated by a paucity of research with a focus on rural IDU.

This study builds on the opioid drug foundation using a previously established (Tookes et al., 2015) methodological framework to focus on the IDU epidemic in a rural US state. ICD-9 \& ICD-10 codes specific to outcomes associated with IDU will be used to define IDU for this study. Additionally, the ICD codes will serve as a basis for retrospectively querying a Medicaid claims database. Services, health outcomes, and patient characteristics will be described in terms of frequency and cost. This project provides an opportunity to develop a more detailed view of insured PWID.

\subsection{Purpose of the Study}

The proposed study investigates the public health and economic consequences of the IDU epidemic as supported by West Virginia Medicaid data. The frequency of injection drug-related health outcomes, service type, charge, and patient characteristics will be described. Specifically, this project seeks to identify if Medicaid claims data have utility for investigating issues experienced by a hard to reach population specifically PWID. Previous studies show that PWID 
tend to use emergency departments as primary care, and present late during the course of disease. (Palepu et al., 2001) These issues combined with a previous lack of widespread electronic medical record utilization has created a challenge in identifying complete data sources for this population. As Medicaid expansion provides coverage to many lower income persons, an opportunity to increase knowledge among multiple medically fragile groups presents itself. (Blumenthal et al., 2015) The proposed study will create a comprehensive profile of a statewide sample of Medicaid insured PWID, including a description of the most frequent and costly services accessed, health outcomes related to IDU and sociodemographic characteristics associated with poor outcomes, frequent service usage, and high cost.

\subsection{Specific Aims and Objectives}

Aim 1: Determine the efficacy of state Medicaid data as a proxy for disease surveillance data in estimating the number of drug overdoses and injection drug related infections in WV between 2014 and 2016.

1. Quantify and describe overdoses, and IDU associated infections among WV Medicaid beneficiaries who received services related to IDU between 2014 and 2016.

2. Compare rates and proportion of overdose and IDU associated infections obtained from Medicaid claims data to surveillance data.

Aim 2: Examine service utilization and characteristics of WV Medicaid beneficiaries who inject drugs between 2014 and 2016.

1. Describe the economic, demographic, and service utilization characteristics of WV Medicaid beneficiaries who received services related to IDU between 2014 and 2016. 
2. Assess the relationship between frequent service utilization and patient characteristics.

Aim 3: Examine the cost of service utilization of WV Medicaid beneficiaries who inject drugs between 2014 and 2016.

1. Quantify the total cost of services, the costliest services, and describe the geographic distribution among PWID and who are covered by Medicaid between 2014 and 2016.

2. Assess the relationship between total costs and patient characteristics and diagnoses.

\subsection{Procedures}

The sample for the proposed project will be comprised of WV Medicaid beneficiaries who have received IDU-related services between 2014 and 2016. This date range was chosen based on the state Medicaid expansion coverage under the ACA began January 1, 2014. Inclusion in this study will be based on specific criteria to determine whether a person injects drugs and if they have experienced an outcome related to IDU. ICD-10 codes will serve as the basis for these criteria. Relevant data elements will be formally requested from the WV Department of Health and Human Services (DHHR), Bureau for Medical Services (BMS), which is charged with operating WV Medicaid and maintaining data. The individual level data that results from the request will not contain any personally identifiable information. Appropriate analyses will be conducted to accomplish each aim and subsequent objective outlined previously.

\subsection{Significance}

Without access to sterile injection equipment and other services offered by harm reduction programs, PWID are more susceptible to adverse health outcomes leading to increased 
morbidity and mortality. (Grebely \& Dore, 2014) Costs associated with providing emergency and recurring IDU-related services to PWID are substantial, and increasingly billed to Medicaid. (Takahashi et al., 2007; Tookes et al., 2015) These factors support the need for a shift towards preventative care and services for PWID. However, harm reduction services are considerably less common in rural areas, where it has been shown there is a significant need. (Des Jarlais et al., 2015) West Virginia continues to struggle with the consequences of IDU, and consistently reports some of the highest rates of overdoses and related infections in the US. (Rudd, Aleshire, et al., 2016; Zibbell, Iqbal, Patel, Suryaprasad, Sanders, Moore-Moravian, Serrecchia, Blankenship, Ward, \& Holtzman, 2015)

Increasing the knowledge within West Virginia of these issues by creating a comprehensive profile of Medicaid beneficiaries who inject drugs by assessing and describing the services received, inclusive of charges, and the geographic distribution of services indicate where prevention strategies, such as harm reduction, could be most useful. As the predominant insurer of PWID nationally, Medicaid programs can benefit from this information to identify avenues for improving healthcare access and containing costs. Additionally, given the paucity of information available on PWID in rural areas, the proposed project will add valuable information to the current body of research.

\subsection{Limitations}

There are limitations to the proposed study. First, this study will use ICD-9 codes to determine beneficiary IDU status and related adverse health outcomes. Some studies suggest that using ICD-9 or -10 codes for research could result in the underreporting of certain conditions. (G. Jones et al., 2012) This may be exacerbated when dealing with complex behaviors like IDU, 
since it can be difficult to ascertain route of drug use from ICD-9 codes. Another drawback to this study design is the retrospective, secondary data analysis component using data not originally collected for research. Because of this, it is not always possible to include all necessary data elements for the analyses to control for issues like confounding. This study will only include PWID who are or were insured by Medicaid between 2014 and 2016. Consequently, PWID who are covered by private insurance or have no insurance coverage will not be included. Past research suggests that this could include a significant proportion of the total population of PWID. (CDC, 2015b; Tookes et al., 2015) Not including those who are uninsured or are insured by plans outside of Medicaid could diminish the generalizability of the proposed study.

\subsection{Organization}

The proposed study will be organized as four separate chapters to include: an extensive literature review (Chapter two), methods section (Chapter three), relevant results (Chapter four), and discussion of and conclusions drawn from results (Chapter five). Chapter two will include a systematic approach to reviewing the current body of research surrounding drug use among Medicaid beneficiaries. Chapter three will discuss the methods employed in defining the study sample, obtaining data, and analyzing data. Chapter four will present the results obtained from analyses in tables, figures, and paragraph form. Finally, chapter five will elaborate on results, synthesize appropriate conclusions, and make recommendations for future research. 


\section{CHA P TER 2: LIT TERA T URE REVIEW}

The US injection drug use (IDU) epidemic is a public health concern associated with negative health outcomes and substantial financial consequences for systems of care. Specifically, IDU is associated with increased overdose deaths, infectious diseases, and cost to healthcare institutions and government subsidized insurers like Medicaid. (Kwon et al., 2009; Rudd, Aleshire, et al., 2016; Takahashi et al., 2010; D. P. Wilson et al., 2015; Zibbell, Iqbal, Patel, Suryaprasad, Sanders, Moore-Moravian, Serrecchia, Blankenship, Ward, Holtzman, et al., 2015) This study seeks to understand the factors associated with the health and financial consequences of IDU using individual level service of IDUs in the state.

\subsection{U.S. Drug Use}

Prescription opioid pain relievers and heroin are opioids that are considered the driving force behind the substantial increase in overdose deaths in the US. Between 1999 and 2015, overdose (OD) rates for prescription opioids and heroin have nearly quadrupled, resulting in more than 500,000 deaths. (C. M. Jones, Logan, Gladden, \& Bohm, 2015) In 2015 over 50,000 drug overdose deaths (ODD) occurred; 30,000 of which were opioid attributable, marking the highest annual ODDs in US history and a nearly three-fold increase since 2002. (Rudd, Seth, et al., 2016) Between 2014 and 2015, states in the North and Southeast census regions experienced statistically significant (p-value <0.05) increases in ODDs, including: West Virginia (41.5 per 100,000), New Hampshire (34.3 per 100,000), Kentucky (29.9 per 100,000), Ohio (29.9 per 100,000), and Rhode Island (28.2 per 100,000). (CDC National Vital Statistics System, 2016; Rudd, Seth, et al., 2016) Adults aged 25 to 64 have the highest ODD rates, however, ODDs increased specifically among 25 to 34 year olds, and men and white, non-Hispanics since 2010 . 
(Rudd, Seth, et al., 2016) Also during this time, heroin ODDs increased by more than $20 \%$ nationwide with each census region reporting a statistically significant increase. (CDC National Vital Statistics System, 2016) Consistent with other drug OD, men between the ages of 25 and 44 had the highest heroin ODs. However, heroin ODD rates are increasing among groups with historically low rates, such as persons aged 18 to 25 years, women, and persons with higher income. (CDC, 2015b) These trends for heroin ODs, specifically, contribute to the growing importance of IDU in the US.

\subsection{U.S. IDU}

IDU is associated with multiple complications in addition to ODs, including economic distress, spread of infectious diseases, mental illness, and reduced access to care. (Centers for Disease \& Prevention, 2012; Palepu et al., 2001; Richardson, Wood, Li, \& Kerr, 2010) Given the upward trend of IDU across the US, the effects of these complications could become more pronounced for not only PWID, but also healthcare institutions and insurers.

\subsubsection{Associated Social and Economic Factors}

Economic distress, unemployment and decreased social functioning are significant aspects of IDU. (Richardson et al., 2010) Studies consistently report an inverse association between IDU and employment, and typically characterize PWID as an impoverished population. For example, one recent, nationally representative study found a strong association between unemployment and illicit drug use. (Compton, Gfroerer, Conway, \& Finger, 2014) Additionally, another study reported a poverty rate in excess of $60 \%$ for a particular cohort of PWID. (Cooper et al., 2016). 
Homelessness has long been tied IDU through overlapping risk factors such as poverty, incarceration, and mental health. (Briggs et al., 2009; Linton, Celentano, Kirk, \& Mehta, 2013; Mizuno et al., 2009) Additionally, evidence supports a temporal relationship between homelessness and IDU initiation or relapse. One recent study found that among those who had stopped injecting, homelessness was associated with IDU relapse, regardless of the duration of homelessness. (Linton et al., 2013) Further, homelessness was also associated with injectionrelated risk behaviors, including needle and cotton sharing, as well as mental illness.

In the US, drug policy seemingly centers on the idea that arrests deter drug-related crimes and drug use in general. (Friedman et al., 2011) Consequently, the US has one of the highest rates of drug-related incarcerations compared to similar countries, with $46 \%$ of all federal offenses relating to drug use. (Prisons, 2017) However, evidence from recent studies suggests that increasing arrests for drug crimes does not decrease drug use, and is costly. One estimate puts the cost per inmate at over $\$ 20,000$, which translates to nearly $\$ 12$ billion to incarcerate inmates with drug-related offenses. (Warren, Gelb, Horowitz, \& Riordan, 2008)

\subsubsection{Associated Comorbidities}

PWID who share injection equipment with infected persons are at an increased risk for bloodborne pathogens, including HIV, viral hepatitis, and soft-tissue infections, like cellulitis and abscesses. In some studies, the estimated prevalence of hepatitis C (HCV), hepatitis B (HBV), and HIV among IDUs was as high as $77 \%, 66 \%$, and $21 \%$ respectively. (Garfein, Vlahov, Galai, Doherty, \& Nelson, 1996; Spiller et al., 2015; Zibbell, Iqbal, Patel, Suryaprasad, Sanders, Moore-Moravian, Serrecchia, Blankenship, Ward, Holtzman, et al., 2015) HIV/HCV coinfection is also common among IDUs, with rates found as high as 92\%. (Peters et al., 2016; Platt et al., 2016) In co-infected persons, HCV may transmit more efficiently, including 
increased risk for perinatal transmission by infected mothers. (Platt et al., 2016) Coinfection can complicate HIV treatment leading to antiretroviral related hepatotoxicity. (Platt et al., 2016; Shepard, Finelli, \& Alter, 2005) Risky behavior engagement, such as unprotected sex, social issues, including unstable housing, lack of access to care, limited availability of sterile injection equipment, and decreased availability of treatment programs, and other societal and healthcare related factors contribute to the spread of infectious diseases. (Altice, Kamarulzaman, Soriano, Schechter, \& Friedland, 2010; Burris \& Strathdee, 2006; Centers for Disease \& Prevention, 2012; Chander, Himelhoch, \& Moore, 2006; Friedland, 2010; Gebo, Keruly, \& Moore, 2003; Regier et al., 1990; Rhodes, Singer, Bourgois, Friedman, \& Strathdee, 2005).

In addition to infectious diseases, PWID tend to have higher rates of depression, personality, and/or anxiety disorders, as well as polysubstance abuse and history of adverse childhood events, which pose significant obstacles to improving health outcomes. (MackesyAmiti, Donenberg, \& Ouellet, 2012, 2014; Sansone, Whitecar, \& Wiederman, 2009) One study reports the prevalence of major mental health disorders at more than one third among PWID. (Kidorf et al., 2004) In particular, 25\% of adults with Schizophrenia have reported illicit drug use in their lifetime. (Van Dorn, Desmarais, Young, Sellers, \& Swartz, 2012) These psychiatric disorders have been shown to be associated with certain IDU risk behaviors, including injection equipment sharing with a high number of people, sharing with strangers, and with people known to be HIV-infected. (Kidorf et al., 2010; Mackesy-Amiti et al., 2014)

\subsubsection{Care Access, Utilization, and Economic Impact of IDU}

Poor access to healthcare and service utilization is a well-documented problem for PWID. (Chitwood, McBride, French, \& Comerford, 1999; McCoy, Metsch, Chitwood, \& Miles, 2001) PWID generally have low access to primary care for a multitude of reasons, including 
inability to set and keep appointment times. Consequently, PWID may use emergency departments as their primary source of healthcare, resulting in later disease stage presentation for care and higher costs. (Fairbairn et al., 2012; French, McGeary, Chitwood, \& McCoy, 2000; Palepu et al., 2001; Solomon, Frank, Vlahov, \& Astemborski, 1991) For example, in one Canadian-based IDU cohort study, $60 \%$ of PWID were frequent users of the emergency department (at least three visits). Among all PWID accessing the emergency department, HIVpositive persons were more likely to be frequent users (adjusted OR 5.4, 95\% CI 3.4-8.6), and have higher costs. (Palepu et al., 2001)

The economic impact of treating IDU related complications can be substantial as it includes infectious diseases, which are largely preventable with access to sterile to injection equipment. In addition to serious medical consequences associated with HIV, including weakened immune system, susceptibility to opportunistic infections, transmissibility, and death, the price of treating one new case into perpetuity is especially burdensome. Treating one HIV case costs approximately $\$ 38,000$ per year, with considerable variation dependent on disease stage. (Fleishman, Monroe, Voss, Moore, \& Gebo, 2016) Further, the most recent available data estimates the total lifetime cost of treating one case of HIV to be between $\$ 253,000$ and $\$ 402,000$ depending on disease stage. (Farnham et al., 2013) Considering that approximately 9\%, or 3,600 new cases of HIV in the US each year identify IDU as risk factor, approximately \$136.8 million are spent on new HIV infections just among PWID. (CDC, 2016)

With more than $60 \%$ of $\mathrm{HCV}$ cases reporting IDU as a risk factor, the financial considerations of IDU and $\mathrm{HCV}$ is equally important. Until recently, $\mathrm{HCV}$ was a chronic condition that typically lasted for the infected patient's lifetime. However, with the advent of direct acting antivirals (DAAs), $\mathrm{HCV}$ is curable in a large percentage of people. A drawback to 
these drugs is the price of the regimens. In the US, certain DAA drugs, such as sofosbuvir, cost as much as $\$ 84,000$ for a 12 -week regimen, or approximately $\$ 1,000$ per pill. (Rosenthal \& Graham, 2016) The most recent available data indicate more than 2,100 acute HCV diagnoses in 2014, which translates to over \$176 million spent on treating HCV among PWID yearly. (CDC, 2014) Moreover, with increasing cure rates comes the possibility of relapse, thus further exacerbating the financial burden of treating $\mathrm{HCV}$.

Although HBV is vaccine preventable, for persons without vaccination, there still is a financial burden associated with treatment. One cost analysis reported the range of costs for treating HBV according to complications and disease stages. (Lee, Veenstra, Iloeje, \& Sullivan, 2004) According to this study, the annual cost for treating chronic HBV was $\$ 761$ per patient; decompensated cirrhosis because of HBV was $\$ 11,459$ per patient; liver transplant was $\$ 86,552$ per patient; transplant follow-up care was $\$ 12,560$ per patient; and hepatocellular carcinoma was $\$ 7,533$ per patient.

Soft-tissue infections and endocarditis are common among PWID who do not have access to sterile injection equipment. One study reported that a third of PWID were treated for softtissue infections like cellulitis and abscesses. (Binswanger et al., 2000) Hospitalizations among PWID with soft-tissue infections can result in significant costs with one recent study estimate of $\$ 4,449$. (Takahashi et al., 2010) Further, another study reported that over a one-year period, PWID treated for soft-tissue infections at a single hospital incurred \$11.4 million in charges. (Tookes et al., 2015) Additionally, 41\% of these charges were billed to Medicaid, the largest insurer for this group. (Tookes et al., 2015) Similarly, endocarditis among PWID has increased over the past decade, with high costs billed predominantly to Medicaid. In a recent study, PWID presenting to a single hospital incurred over $\$ 50,000$ per hospitalization for endocarditis, and 
most (42\%) were insured by Medicaid. (Fleischauer et al., 2017) Although soft-tissue infections are acute and readily treatable, the cost of consistently treating PWID is formidable combined again with late stage presentation for care.

Despite poor primary care utilization among PWID and subsequently higher costs, effective public health interventions, such as harm reduction can alleviate some negative health outcomes and reduce costs. Harm reduction refers to strategies aimed at diminishing health risks associated with behaviors like IDU. (D. P. Wilson et al., 2015) When considering harm reduction for IDU, syringe exchange programs (SEP) are one of the more common methods employed, and seek to reduce the spread of bloodborne pathogens and soft-tissue infections. The underlying function of SEPs involves the distribution of sterile needles, syringes, and injection equipment to PWID, while collecting and safely discarding used paraphernalia.

SEPs implemented in a variety of locations worldwide and in the US have been effective in reducing the spread of infectious diseases. (Bastos \& Strathdee, 2000; Kwon et al., 2009; Vickerman et al., 2006; D. P. Wilson et al., 2015) A systematic review conducted by Wodak et al found 23 studies reported SEPs reduced risk behaviors associated with HIV. (Wodak \& Cooney, 2005) In particular, one of those studies reported significant decreases in HIV incidence after the implementation of a SEP (4\% - 1\%). (Jarlais et al., 2005) Other studies have found as much as an $80 \%$ reduction in $\mathrm{HIV}, \mathrm{HCV}$, and other bloodborne pathogen incidence among those began injecting drugs after the implementation of SEPs. (Somaini et al., 2000)

SEPs are successful in reducing the spread of infections because of the effectiveness in reducing the sharing of needles and equipment. A number of studies report PWID who also participate in SEPs are less likely to self-report sharing needles, syringes or injection equipment. One of those studies found a protective effect of participation in a SEP on sharing behavior 
$(\mathrm{aOR}=0.77,95 \% \mathrm{CI}=0.67-0.88)$. (Holtzman et al., 2009) Similarly, a separate study found that participation in a SEP reduced the odds of receptive needle sharing by nearly $60 \%$ (OR=0.33 $\mathrm{CI}=0.23-0.46)$, lending needles by $45 \%(\mathrm{OR}=0.55 \mathrm{CI}=0.41-0.75)$, and sharing equipment by $30 \%(\mathrm{OR}=0.70 \mathrm{CI}=0.52-0.95)$. (Huo \& Ouellet, 2007). Another important function of SEPs is the collection and disposal of used needles or syringes, ensuring the potentially hazardous materials are discarded appropriately, further reducing sharing behaviors and risk to the general public. However, relatively few US-based studies have investigated needle return rates at SEPs. (Ksobiech, 2004) One literature review found that of US-based studies, the overall average needle return rate was approximately 90\%. (Ksobiech, 2004) Although, there was significant variation between studies (68\%-102\%). (Paone, Jarlais, Caloir, Clark, \& Jose, 1995)

The evidence supporting the effectiveness of SEPs in reducing the spread of bloodborne pathogens and other infections among PWID is abundant. (Holtzman et al., 2009; Hurley, Jolley, \& Kaldor, 1997; Jarlais et al., 2005; Kwon et al., 2009) In addition, SEPs tend to be a costeffective intervention by averting costs of new infections while costing relatively little to operate. (D. P. Wilson et al., 2015) According to one estimate, implementing and maintaining a SEP costs approximately \$23-\$71 per person accessing services per year. (D. Wilson et al., 2014) Further, one study found that in addition to significantly reducing HIV incidence, a SEP reported an approximate $\$ 5$ saved as a result of infection aversion for every $\$ 1$ invested in providing services. (Kwon et al., 2009) Moreover, considering the cost of treating new cases of HIV ( $\sim 136$ million per year) and HCV ( \$176 million per year) just among PWID, the economic benefits of having optimal coverage of SEP could be profound. (Farnham et al., 2013; Rosenthal \& Graham, 2016) This is especially true for economically depressed, rural regions of the US where IDU is becoming more of an issue. (Des Jarlais et al., 2015) 
IDU is a highly stigmatized behavior, and significant barriers prevent many PWID from accessing treatment and harm reduction services. Notable barriers include availability of services, distance from services, fear of police, and stigmatization among others. (Allen, Ruiz, \& Jones, 2016; Beletsky et al., 2014) In one study, police encounters were an important barrier to accessing a SEP with $52 \%$ of clients having been stopped by police, $10 \%$ reporting syringe confiscation, resulting in persons police encounters becoming less likely to access the SEP (adjusted $\mathrm{OR}=0.59 ; \mathrm{CI}=0.40-0.89$ ). (Beletsky et al., 2014) Availability of harm reduction services in rural areas is also of concern because of the relatively few programs in operation. (Des Jarlais et al., 2015) Addressing these barriers could not only improve health outcomes among PWID, but also reduce spending associated with increased utilization of emergency services and treating new bloodborne infections.

With the passing of the Affordable Care Act in 2010 came a large-scale expansion of Medicaid to include more lower-income Americans. (Blumenthal et al., 2015) Medicaid is a government subsidized health insurance program, administered at the state-level, which provides coverage to low-income adults, children, and pregnant women among others. Second only to employer-based insurance, Medicaid is one of the largest insurers of Americans, covering approximately $20 \%$ of the population. (Foundation, 2015) Although there is no estimate of the number of PWID covered by Medicaid, indications are that it is a large proportion. A number of studies conducted on an array of topics related to IDU have shown that Medicaid is often the predominant insurer among PWID. (C. M. Jones et al., 2015; Knowlton et al., 2001; Takahashi et al., 2010; Tookes et al., 2015; Yehia et al., 2014) The proportion of PWID covered by Medicaid varied between studies, with the largest reported at approximately 60\%. (Yehia et al., 2014) One particular study investigated health insurance status among persons with HIV were more likely 
to be insured by Medicaid (60\%) with Medicare covering 19\%. (Yehia et al., 2014) The CDC estimates that $5 \%$ of persons who overdosed on injected heroin were Medicaid covered and this was the only consistent insurance coverage. (CDC National Vital Statistics System, 2016)

\subsection{IDU and Rurality}

\subsubsection{IDU in Rural US}

Rural states are disproportionately impacted with higher rates of opioid abuse.

Traditionally considered an urban problem, rural drug abuse has increased over the past two decades. (Dombrowski, Crawford, Khan, \& Tyler, 2016; Gfroerer, Larson, \& Colliver, 2007; Zibbell, Iqbal, Patel, Suryaprasad, Sanders, Moore-Moravian, Serrecchia, Blankenship, Ward, Holtzman, et al., 2015) The most significantly impacted states are those in the rural, central Appalachian region which contains states with some of the highest age-adjusted rates of ODDs.

(Rudd, Seth, et al., 2016) Although not widely reported, studies have identified important social and demographic differences between rural and urban drug abusers, including: age of drug use initiation is younger among rural drug users; persons tend to be white and non-Hispanic; and have different initiation patterns for IDU (Young, Havens, \& Leukefeld, 2012) (Paulozzi, 2012) (Young et al., 2012) Heroin overdoses have permeated rural regions. Fentanyl encounters, specifically, are on the rise in the central Appalachian region. (CDC, 2015a) Fentanyl, a synthetic opioid pain reliever that can be up to 100 times stronger than morphine, is a common drug of choice and manufactured in a method which increases the probability of OD. (Algren et al., 2013) Between 2014 and 2015, fentanyl overdose death rates increased by $72 \%$, resulting in 9,500 deaths nationwide. (Rudd, Seth, et al., 2016) 


\subsubsection{Social and Economic Factors in Rural US}

Compared to the rest of the US, the rural, central Appalachian region struggles with unemployment and economic hardship. As of 2017, the unemployment rates for certain central Appalachian states, like West Virginia (4.9) and Kentucky (5.0), were among the worst in the nation (4.5). In 2015 median household income was significantly lower than the national average ( $\$ 33,000$ v. $\$ 53,000)$; and nearly $25 \%$ of central Appalachians were living in poverty compared to the $14 \%$ national average. (Pollard \& Jacobsen, 2017)The Appalachian Regional Commission (ARC) created an index, using unemployment rates, poverty rates, and income, to assess the economic status of Appalachian counties. According to this index, in 2016, the majority of the 84 Appalachian counties classified as 'economically distressed' were in the central Appalachian region. These economic characteristics factor into the current opioid epidemic plaguing this area. Studies have drawn a connection between economic hardship and substance abuse within Appalachia and abroad. (Compton et al., 2014; Richardson et al., 2010) The situation in post-recession Appalachia is comparable to the collapse of the Soviet Union, the other region in the world which has faced increased injection drug use following economic hardships. Following the collapse, former Soviet Union nations experienced increases in unemployment, depression, suicide, and substance abuse. (Atlani, Carael, Brunet, Frasca, \& Chaika, 2000; McKee, 2005)

\subsubsection{IDU Associated Infectious Diseases: Rural v. Urban}

IDU and infectious diseases are increasing in importance in rural areas with increased rates of HCV and HBV. (Suryaprasad et al., 2014) Between 2006 and 2012, there was a 364\% increase in the number of acute cases of HCV among people 30 and younger within central Appalachia, which includes Kentucky, West Virginia, Tennessee, and Virginia. Among these 
cases, $73 \%$ indicated IDU as a risk factor. (Zibbell, Iqbal, Patel, Suryaprasad, Sanders, MooreMoravian, Serrecchia, Blankenship, Ward, Holtzman, et al., 2015) HBV increased in the same states while remaining stable throughout the rest of the US. (Harris et al., 2016) Between 2006 and 2013, there was a 114\% increase in acute HBV cases reported from West Virginia, Kentucky, and Tennessee, with a majority indicating IDU. (Harris et al., 2016) HIV infections among rural PWID has also been a significant issue recently. In 2015, an HIV outbreak of IDUs in rural Indiana led to 135 new infections with $80 \%$ reporting a history of IDU. (Conrad, Bradley, Broz, Buddha, Chapman, Galang, Hillman, Hon, Hoover, Patel, Perez, Peters, Pontones, Roseberry, Sandoval, Shields, Walthall, Waterhouse, Weidle, Wu, Duwve, et al., 2015)

In 2016, the CDC conducted a nationwide assessment of HCV/HIV risk among IDUs at the county level. (Van Handel et al., 2016) This study revealed the majority of counties at the highest risk for increased rates of IDU-related HCV and HIV were rural and concentrated in the central Appalachian region. Additionally, half of WV counties were among the most vulnerable to the spread of HCV and HIV among PWID, including two of the top ten most vulnerable counties. (Van Handel et al., 2016)

\subsubsection{Care Access: Rural v. Urban}

In general, there are significant disparities in health care access between rural and urban areas of the US. (Douthit, Kiv, Dwolatzky, \& Biswas, 2015) Certain barriers affecting health care access are specific to rural regions, and include cultural and financial constraints, scarcity of services, lack of trained physicians, insufficient public transport, and poor availability of broadband internet services. (Douthit et al., 2015) Consequently, rural inhabitants tend to be in poorer health and have less access to a regular physician compared to their urban counterparts. 
(Douthit et al., 2015) Similar disparities exist for rural and urban PWID, understated by the availability of access to harm reduction services.

As of 2014, over 200 SEPs were in operation across the US. (Des Jarlais et al., 2015) However, according to a recent report, significantly fewer SEPs and harm reduction services were available outside of urban centers. (Des Jarlais et al., 2015) Additionally, rurally based SEPs exchanged far fewer needles, had smaller budgets, and were more likely to report barriers to optimal service delivery, including lack of full-time or paid staff, funding, and problems recruiting participants. (Des Jarlais et al., 2015) With increased heroin overdoses, a recent outbreak of HIV among PWID in a rural community, and a reported increase in vulnerability to the spread of HIV and HCV among PWID in rural counties, it is apparent there is a need for more SEPs and harm reduction services in rural areas of the US. (Conrad, Bradley, Broz, Buddha, Chapman, Galang, Hillman, Hon, Hoover, Patel, Perez, Peters, Pontones, Roseberry, Sandoval, Shields, Walthall, Waterhouse, Weidle, Wu, Duwve, et al., 2015; Rudd, Seth, et al., 2016; Van Handel et al., 2016)

\subsection{West Virginia}

West Virginia (WV) is a rural state in central Appalachian with a decreasing population currently at 1.8 million. In terms of sociodemographic characteristics, WV is a predominantly white and non-Hispanic (93.6\%) state that has an unemployment rate of $6 \%$ and almost 1 in 5 persons living in poverty. (Statistics, 2017; "United States Census Bureau: Statistical Abstract of the United States: 2011 (130th Edition)," 2011). 


\subsubsection{Drug Overdoses}

Compared to the rest of the US, West Virginia has the highest opioid ODD rate at 41.5 deaths per 100,000 people with Kentucky as the next closest at 34.3 deaths per 100,000. (CDC National Vital Statistics System, 2016) The WV age-adjusted ODD rate has increased 10-fold since 1999 , and by $16.9 \%$ since 2014 . Among states reporting information on prescription and heroin ODDs, WV ranks as one of the highest nationally, with rates of 19.8 deaths and 11.8 deaths, respectively, per 100,000 people. (CDC National Vital Statistics System, 2016)

\subsubsection{IDU Associated Infectious Diseases}

As of 2014, WV has the second highest rate of HCV and the highest rate of HBV in the US at 3.4 per 100,000 and 10.1 per 100,000 respectively with additional studies showing a continuing increase among IDUs. (CDC, 2014; Harris et al., 2016; Van Handel et al., 2016; Zibbell, Iqbal, Patel, Suryaprasad, Sanders, Moore-Moravian, Serrecchia, Blankenship, Ward, Holtzman, et al., 2015) Notably, the HBV rate is nearly triple that of the next highest state, Kentucky, which reported 3.7 cases per 100,000 people in 2014. (CDC, 2014) Despite these disproportionately high rates of HCV and HBV, state HIV surveillance data shows one of the lowest rates of new HIV infections at 4.7 cases per 100,000 people. (CDC, 2016) However, considering the upward trend of HCV and HBV rates among PWID, increases in HIV rates may follow as a result of overlapping risk factors.

\subsubsection{Care access}

Access to care, especially infectious disease care is limited to the larger cities. Further, many of the barriers that inhibit the utilization of care and services in rural regions of the US are likely to affect similar areas in WV. Consequently, high-risk populations especially, like PWID, 
have fewer options for healthcare, and may have worse outcomes. One way the state Department of Health and Human Resources (DHHR) attempts to combat these issues is through bolstering infectious disease testing. According to a recent health advisory, the WV DHHR recommended screening for HIV, HCV, and HBV routinely and simultaneously, reporting clusters of HIV within 24 hours, and providing screening and counseling. Specifically, the WV DHHR recommends testing and counseling be conducted in opioid substitution therapy programs (e.g. methadone), buprenorphine-prescribing facilities, drug rehabilitation or detoxification programs, mental health service providers for substance use disorder, harm reduction and syringe service programs, emergency departments and in-patient settings, jails and prisons. Although screening is important, investing in and expanding coverage of interventions specific to PWID, like harm reduction, could reduce the impact of IDU in West Virginia. (DHHR, 2017) 


\section{CHA P TER 3: METHODS}

\subsection{Participants}

Secondary data from Medicaid-insured individuals residing in West Virginia diagnosed with conditions related to injection drug use (IDU) between the fiscal years 2014 and 2016 were included in this study. Medicaid eligibility is based on modified adjusted gross income relative to the federal poverty level (FPL). (CMS, 2017) Adults in West Virginia at 133\% of the FPL are automatically eligible for Medicaid coverage. The International Classification of DiseasesRevision 10 (ICD-10) was used to assess IDU within this population, as well as comorbid conditions relating to IDU. The time period for this study was chosen because the state Medicaid expansion coverage under the Affordable Care Act (ACA) began January 1, 2014. Any individuals under the age of 18 were excluded from these analyses.

\subsection{Measures}

The classification of IDU and associated comorbid conditions were based on a predetermined list of ICD-9 and 10 codes. Both ICD-9 and 10 codes were used because WV switch from ICD-9 to -10 in 2015 . Since few, if any, ICD-9 or 10 codes relate specifically to IDU and infections arising from IDU, a previously established framework was used to define these measures in this study. (Tookes et al., 2015) This framework defines IDU and related infections as having one or more drug abuse diagnoses with one or more infection diagnoses. Table 1 outlines ICD-9 and 10 codes used to determine drug abuse. Table 2 lists ICD-9 and 10 codes used to determine IDU-related infections. Overdoses (OD) were defined according to the drug-specific poisoning ICD-10 code. 
Clinical conditions, e.g HIV, acute HCV infection, and endocarditis, were defined using indicator variables. Variables race and county of residence were collapsed into smaller categories to avoid small cell counts. Race was collapsed into black, white, other, and unknown, with other referring to Hispanic or native American/native Alaskan. A person's county of residence was collapsed into public health district, which was defined by surveillance reports conducted by the West Virginia Department of Health and Human Resources (WV DHHR). Figure 1 provides a graph of these public health districts.

Figure 1: West Virginia public health districts according to WV DHHR surveillance reports

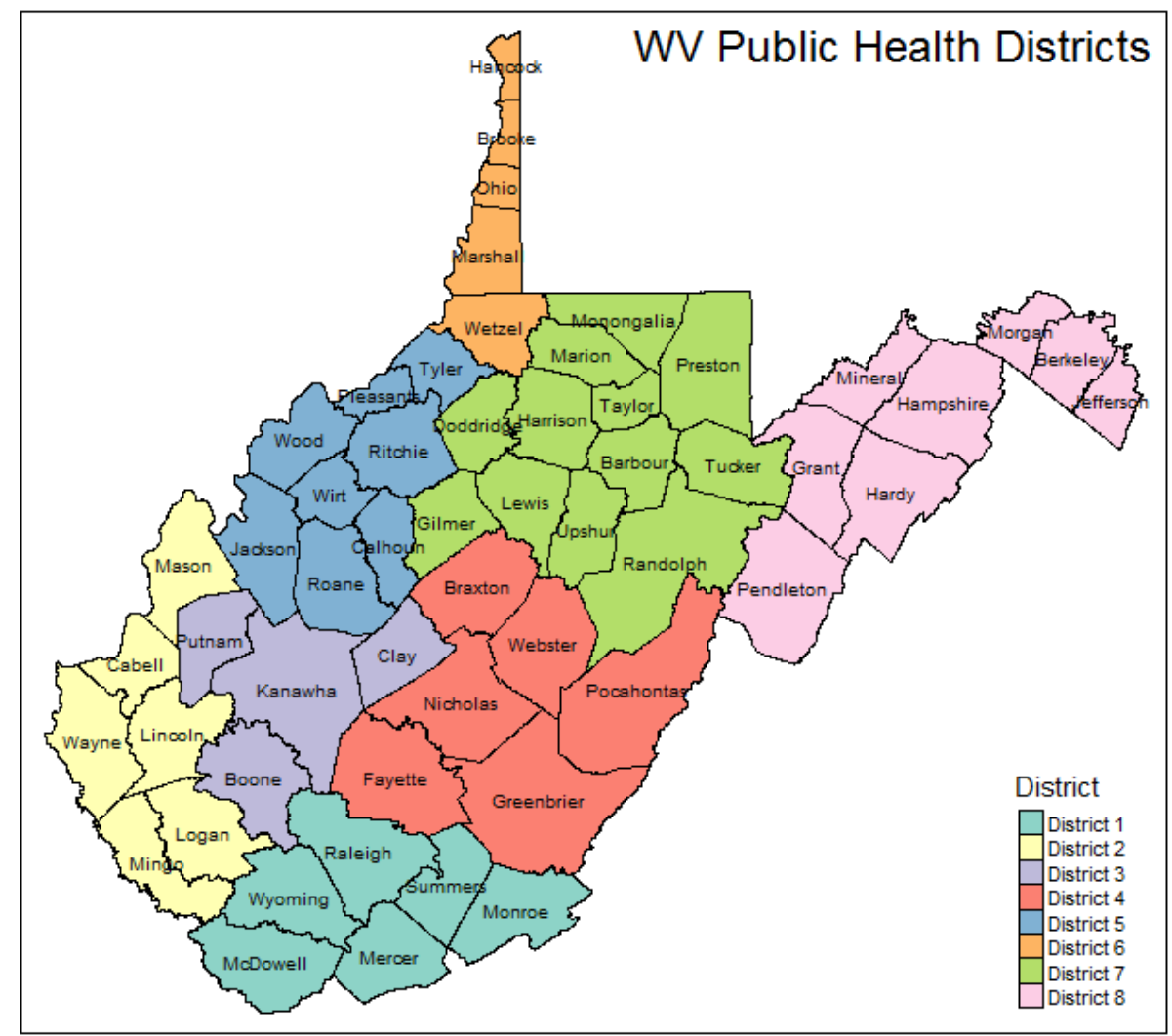


Table 1: ICD-9 and 10 codes used to define drug abuse

\begin{tabular}{|c|c|c|}
\hline $\begin{array}{l}\text { Drug Abuse } \\
\text { Diagnoses }\end{array}$ & ICD-9 Codes & ICD-10 Codes \\
\hline Opiates & $\begin{array}{l}\text { E850.0; E850.2; 304.00-.03; 304.70-.73; 305.50-.53; } \\
965.01 ; 965.09\end{array}$ & $\begin{array}{l}\text { F11.20-.21; F19.20-.21; F11.10; T40.1X1A- } \\
.1 \mathrm{X} 4 \mathrm{~A} ; \mathrm{T} 40.2 \mathrm{X} 1 \mathrm{~A}-.2 \mathrm{X} 4 \mathrm{~A}\end{array}$ \\
\hline Cocaine & $304.21-.23 ; 305.60-.63 ; 970.81$ & F14.20-.21; F14.10; T40.5X1A-.5X4A; \\
\hline Amphetamines & $304.41-.43 ; 305.71-.73 ; 969.72$ & F15.20-.21; F15.10; T43.621A-.624A \\
\hline Sedatives & $305.40-.43$ & F13.10 \\
\hline Other $^{1}$ & $\begin{array}{l}304.60-.63 ; 304.80-.83 ; 304.90-.93 ; 305.90-.93 ; \\
648.33 ; 648.34\end{array}$ & F19.20-.21; F18.10; 099.321-.323; 099.325 \\
\hline
\end{tabular}

', Other' includes unspecified drug dependence, combination of drug dependence, and drug dependence relating to pregnant women. 
Table 2: ICD-9 and 10 codes used to define IDU-related infections

\begin{tabular}{|c|c|c|}
\hline $\begin{array}{l}\text { Infection } \\
\text { Diagnoses }\end{array}$ & ICD-9 Codes & ICD-10 Codes \\
\hline Endocarditis & $\begin{array}{l}\text { 112.81; 421.0; 421.1; 421.9; 424.0-.3; 424.90; 424.91; } \\
424.99\end{array}$ & $\begin{array}{l}\text { B37.6; I33.0; I39; I33.9; I34.0; I34.8; I35.0 -.2; } \\
\text { I35.8; I35.9; I36.0; I36.8; I37.0; I37.8; I38; I39 }\end{array}$ \\
\hline $\begin{array}{l}\text { Sepsis or } \\
\text { bacteremia }\end{array}$ & $\begin{array}{l}\text { 038.0; 038.10-.12; 038.19;038.2; 038.3; 038.40-.44; } \\
\text { 038.49; 038.8; 038.9; 415.12; 422.92; 449; 785.52; } \\
\text { 790.7; 995.90-.92 }\end{array}$ & $\begin{array}{l}\text { A40.9; A41.2; A41.01-.02; A41.1; A40.3; A41.4; } \\
\text { A41.50; A41.3; A41.51-.53; A41.59; A41.89; } \\
\text { A41.9; I26.90; I40.0; I76; R65.21; R78.81; R65.10; } \\
\text { R65.20 }\end{array}$ \\
\hline Osteomyelitis & 730.00-.29; 730.90-.99 & $\begin{array}{l}\text { M86.10; M86.20; M86.119; M86.219; M86.129; } \\
\text { M86.229; M86.139; M86.239; M86.149; M86.249; } \\
\text { M86.159; M86.259; M86.169; M86.269; M86.179; } \\
\text { M86.279; M86.18; M86.28; M86.19; M86.29; } \\
\text { M86.60; M86.619; M86.629; M86.639; M86.642; } \\
\text { M86.659; M86.669; M86.679; M86.68; M86.69; } \\
\text { M86.9; M46.20; M46.30 }\end{array}$ \\
\hline $\begin{array}{l}\text { Skin or soft tissue } \\
\text { infections }\end{array}$ & $\begin{array}{l}040.0 ; 324.0 ; 324.1 ; 324.9 ; 326 ; 567.22 ; 567.31 ; \\
567.38 ; 569.5 ; 572.0 ; 590.1 ; 681.00-.02 ; 681.10 ; \\
681.11 ; 681.9 ; 682.0-.9 ; 709.8 ; 728.86 ; 723.6 ; 729.30 ; \\
729.39 ; 785.4\end{array}$ & $\begin{array}{l}\text { A48.0; G06.0-.2; G09; K65.1; K68.12; K68.19; } \\
\text { K63.0; K75.0; N10; L03.019; L03.029; L03.019; } \\
\text { L03.039; L03.049; L03.019; L03.029; L03.39; } \\
\text { L03.49; K12.2; L03.211; L03.212; L03.213; } \\
\text { L03.221; L03.222; L03.319; L03.129; L03.317; } \\
\text { L03.811; L03.818; L03.891; L03.898; L03.90; } \\
\text { L03.91; L94.2; L98.8; M72.6; M54.02; M79.3; I96 }\end{array}$ \\
\hline HIV/AIDS & 042; 079.53; 795.71; V08 & B20; Z21; Z20.6 \\
\hline Hepatitis C, Acute & $070.51 ; 070.41$ & B17.10; B17.11 \\
\hline Hepatitis B, Acute & $070.21 ; 070.20 ; 070.30$ & B16.9; В16.1; В16.0 \\
\hline
\end{tabular}




\subsection{Design}

This study was a retrospective, secondary data analysis of payer information collected on West Virginia Medicaid participants between the fiscal years 2014 and 2016. Requested variables included demographic characteristics, services rendered, and the cost of those services. Demographic variables included age, gender, race/ethnicity, and county of residence. Service variables included provider/facility type, claim type, service category, and the date the service was provided. Cost variables included prescription, and medical service costs. Data were housed on a secure drive with restricted access. West Virginia University's Institutional Review Board approved the protocol for this study.

\subsection{Procedure}

The data for this study was formally requested through the West Virginia Department of Health and Human Resources' external analytic request mechanism. The data request was based on a pre-determined list of ICD codes which related to IDU, e.g. HCV, HIV, HBV, soft tissue infections, ODs, etc. The cost of these data was $\$ 6,450$. Specific protections were employed for these data, and included access restrictions and storage on secure drives. Upon receiving the requested data, preprocessing techniques were used to clean and merge data into workable datasets. Data analysis followed in accordance with the aims and objectives of this study.

\subsection{Outcomes}

The underlying goal of this dissertation project was to determine specific service utilization and associated costs, describe health outcomes, and develop a comprehensive profile of PWID in WV using statewide, individual service-level data. The outcomes for the project were: 1 . determining the viability of state Medicaid data as a source of identifying drug 
overdoses and drug-related infections by comparing to surveillance data using equivalence testing; 2 . understanding the service utilization patterns and potential associations with certain characteristics of PWID; 3. estimating the cost attributable to specific services. Topics investigated under each of these outcomes included: overdoses, viral infections, soft tissue infections, geographic distributions, most common services accessed, and most costly services accessed.

\subsection{Statistical Analysis}

Categorical variables, e.g. race, gender, service type, and clinical diagnoses, were described using frequency and contingency tables with counts and percentages. Spatial variables, e.g. county of residence and provider, were plotted using Geographic Information Systems (GIS) packages ('tmap' and 'rgdal') in R to assess the distribution of PWID insured by Medicaid within WV. Continuous variables, e.g. age, medical claims cost, and prescription claims cost, were summarized using mean, median, minimum, maximum, interquartile range, and skew. Scatterplots and histograms were utilized in order to visualize these continuous data to identify potential outlying subjects or clusters, and to assess skew.

Given the size of claims data for a statewide population, asymptotic statistical tests, e.g. $\chi^{2}$ test, were used to assess relationships among the categorical variables (e.g. race and service types) to assess unadjusted relationships. Where there were small cell sizes $(<5)$, Fisher's exact

test replaced the $\chi^{2}$ test. Pearson's correlation coefficient was used to assess the relationship between continuous variables, e.g. age versus medical claims cost. In the multivariate data analysis, linear regression models were used for continuous outcome variables, logistic regression models were used for binary outcome variables and ordinal logistic regression models 
were used for the ordinal scale outcome variables. P-values were used to comment on the strength of the association.

For all formal hypothesis testing and confidence interval construction, an alpha-level of 0.05 was used. All analyses will be conducted using R version 3.3.3.

\subsubsection{Analyses for Specific Aim 1:}

Aim 1: Determine the efficacy of state Medicaid data as a proxy for disease surveillance data in estimating the number of drug overdoses and injection drug related infections in $W V$ between 2014 and 2016.

The prevalence of IDU and correlates were calculated using the requested ICD-9 and 10 codes. In order to determine if Medicaid claims data can be used as a proxy for measuring IDU and associated infections in West Virginia (WV), calculated rates and/or proportions were compared to state estimates obtained from various surveillance data. The full Medicaid claims dataset, rather than the IDU subset, was used since IDU is only one of the risk behaviors for HIV, HCV, and HBV. Medicaid claims utility, as a proxy to surveillance data, was assessed using equivalency testing between the two data sources. Specifically, tests for equivalency between Medicaid claims and surveillance data (gold standard) with an equivalence margin of +/- $50 \%$ change relative to state surveillance rates served as the basis for determining the viability of Medicaid claims data in estimating IDU. Since there is little information to support a specific equivalence margin for rare events, the choice to use relative percent change for an equivalence margin is loosely based on the CDC's use of statistically significant changes in heroin OD rates between calendar years. Table 3 reports the rates of each diagnosis according to state surveillance data, and the corresponding equivalence margin. 
Table 3: Rates of injection drug use (IDU) related diagnoses obtained from 2015 state surveillance reports with equivalence margin of $+/-50 \%$ relative change.

\begin{tabular}{l|l|l|l}
\cline { 2 - 4 } & \multicolumn{2}{c|}{ State Surveillance } & \multicolumn{1}{c}{$\begin{array}{c}\text { Equivalence } \\
\text { Margin }\end{array}$} \\
\hline Diagnoses & n & Rate per 100,000 & $\mathbf{+ / - 5 0 \%}$ \\
\hline Hepatitis C, acute & 63 & 3.4 & $(1.7,5.1)$ \\
Hepatitis B, acute & 272 & 14.7 & $(7.4,22.1)$ \\
Persons Living with HIV/AID & 1,988 & 107.8 & $(53.9,161.7)$ \\
Heroin Poisoning & 327 & 17.7 & $(8.9,26.6)$ \\
\hline
\end{tabular}

${ }^{\mathrm{a}}$ Sources: West Virginia Department of Health and Human Resources; WV Poison Center Annual Report

\subsubsection{Analyses for Specific Aim 2}

Aim 2: Examine service utilization and characteristics of WV Medicaid beneficiaries who inject drugs between 2014 and 2016.

Service utilization was described according to inpatient, emergency room, and substance abuse/mental health services. Observations were categorized based on frequency of service utilization, with cut points indicating low, medium and high frequency usage. Cut points were based on previous studies investigating emergency room, inpatient, and substance abuse service utilization. (Lin, Bharel, Zhang, O'Connell, \& Clark, 2015) For inpatient services, cut points at one service, two services, and three or more services accessed during the study period were used. For both emergency room and mental health/substance abuse services, cut points were at one to two services, three to five services, and six or more services. Since the outcome variable is naturally ordered, ordinal logistic regression was used to assess the relationship between patient characteristics, e.g. demographics, diagnoses, and district of residence, and frequency of service usage. The proportional odds assumption was assessed graphically. 


\subsubsection{Analyses for Specific Aim 3}

Aim 3: Examine the cost of service utilization of WV Medicaid beneficiaries who inject drugs between 2014 and 2016.

Linear modelling of total costs for care and services was used to assess relationships with patient characteristics, e.g. demographics, diagnoses, service types, and district of residence. Two models were built, including one with an outcome variable of the total cost for medical services only, and one with an outcome variable of the total cost for medical services and prescription drugs. In both models, histograms of the outcome variables showed heavy right skew. Subsequently, the outcome variables were log transformed to satisfy distributional assumptions of multiple regression. Diagnostic plots, e.g. residual and Q-Q plots, were used to assess any other assumption violations. Stepwise model selection with AIC was used to obtain the final models. Adjusted effects were obtained from the final models to determine the highest costs according to patient characteristics. These effects were back transformed to allow for interpretation in terms of percent change relative to the reference group. 


\section{H A P T E R 4: R E S UL T S}

\subsection{Description of Sample}

Table 3 describes characteristics of the sample. There were 5,082 WV Medicaid beneficiaries identified as PWID, utilizing 14,414 services between fiscal years 2014 and 2016. Of these individuals, men comprised $51.6 \%(n=2,622)$ of the sample, while women accounted for $48.3 \%(n=2,457)$. White race was the most common reported $(60.5 \%$; $n=3,075)$, followed by 'other' $(4.6 \% ; \mathrm{n}=236)$, and black $(1.9 \% ; \mathrm{n}=98)$. A large number of individuals' race was reported as unknown $(32.9 \% ; \mathrm{n}=1,673)$. The median age was 34 years $(18-85$ years $)$, and the majority of persons had a plan type of fee-for-service $(75.5 \% ; n=3,822)$. The median total cost per person attributable to medical claims and prescription claims was $\$ 794.90$ ( $\$ 0.00-\$ 203,800)$, and $\$ 986.60$ ( $\$ 0.00$ - $\$ 158,000)$ respectively. The median number of total services accessed per person was four $(1-84)$, and the median number of total prescriptions per person was 28 ( 1 616). Most individuals resided in District $2(23.6 \% ; \mathrm{n}=1,197)$ and District $3(20.7 \% ; \mathrm{n}=1,052)$ 
Table 4: Characteristics of West Virginia (WV) Medicaid beneficiaries who inject drugs $(\mathrm{n}=5,082), 2014-2016$

\begin{tabular}{|c|c|}
\hline Characteristic & $\mathrm{n}(\%)$ \\
\hline \multicolumn{2}{|l|}{ Gender } \\
\hline Men & $2,622(51.6)$ \\
\hline Women & $2,457(48.3)$ \\
\hline \multicolumn{2}{|l|}{ Race } \\
\hline Black & $98(1.9)$ \\
\hline White & $3,075(60.5)$ \\
\hline Other & $236(4.6)$ \\
\hline Unknown & $1,673(32.9)$ \\
\hline \multicolumn{2}{|l|}{ Claim Plan Type } \\
\hline Managed Care & $1,247(24.5)$ \\
\hline Non Managed Care/Fee for & $3,835(75.5)$ \\
\hline Service & \\
\hline \multicolumn{2}{|l|}{ District } \\
\hline District 1 & $734(14.4)$ \\
\hline District 2 & $1,197(23.6)$ \\
\hline District 3 & $1,052(20.7)$ \\
\hline District 4 & $275(5.4)$ \\
\hline District 5 & $288(5.7)$ \\
\hline District 6 & $332(15.9)$ \\
\hline District 7 & $558(11.0)$ \\
\hline District 8 & $640(12.6)$ \\
\hline \multirow[t]{2}{*}{ Total } & 5,082 \\
\hline & Median (min - max) \\
\hline Age & $34(18-85)$ \\
\hline Medical Claims Cost & $\$ 794.90(\$ 0.00-\$ 203,800)$ \\
\hline Prescription Claims Cost & $\$ 986.60(\$ 0.00-\$ 158,000)$ \\
\hline Number of Services Accessed & $6(1-88)$ \\
\hline Number of Prescriptions & $28(1-616)$ \\
\hline
\end{tabular}

Table 4 shows the geographic distribution of Medicaid insured PWID by WV county during the study period. Since these data are based on fiscal years, July - December is included for 2014, all of 2015 is included, and January - June is included for 2016. Kanawha county was the most commonly reported county of residence ( $n=770 ; 2014-2016)$, followed by Cabell 
$(\mathrm{n}=651 ; 2014-2016)$ and Berkeley $(\mathrm{n}=361 ; 2014-2016)$. Figure 2 provides a visual representation of the distribution of Medicaid insured PWID within WV.

Table 5: Number of WV Medicaid beneficiaries who inject drugs by county of residence, 20142016

\begin{tabular}{l|l|l|l|l|l|l|l|l}
\hline County & $\mathbf{2 0 1 4}$ & $\mathbf{2 0 1 5}$ & $\mathbf{2 0 1 6}$ & County & $\mathbf{2 0 1 4}$ & $\mathbf{2 0 1 5}$ & $\mathbf{2 0 1 6}$ \\
\hline Barbour & 9 & 8 & 3 & Mineral & 12 & 20 & 2 \\
Berkeley & 84 & 217 & 79 & Mingo & 21 & 33 & 13 \\
Boone & 39 & 43 & 10 & Monongalia & 44 & 76 & 25 \\
Braxton & 7 & 10 & 6 & Monroe & 1 & 7 & 1 \\
Brooke & 12 & 26 & 6 & Morgan & 3 & 27 & 5 \\
Cabell & 175 & 360 & 140 & Nicholas & 15 & 24 & 6 \\
Calhoun & 2 & 5 & 1 & Ohio & 42 & 53 & 28 \\
Clay & 6 & 10 & 4 & Pendleton & 0 & 5 & 1 \\
Doddridge & 2 & 5 & 0 & Pleasants & 1 & 2 & 1 \\
Fayette & 32 & 70 & 19 & Pocahontas & 4 & 4 & 1 \\
Gilmer & 2 & 3 & 0 & Preston & 13 & 26 & 10 \\
Grant & 5 & 6 & 2 & Putnam & 42 & 59 & 27 \\
Greenbrier & 15 & 36 & 11 & Raleigh & 100 & 149 & 45 \\
Hampshire & 11 & 14 & 7 & Randolph & 21 & 31 & 12 \\
Hancock & 38 & 51 & 17 & Ritchie & 1 & 5 & 1 \\
Hardy & 5 & 6 & 4 & Roane & 4 & 12 & 3 \\
Harrison & 39 & 59 & 15 & Summers & 15 & 23 & 5 \\
Jackson & 12 & 25 & 8 & Taylor & 4 & 11 & 2 \\
Jefferson & 39 & 68 & 18 & Tucker & 2 & 1 & 0 \\
Kanawha & 250 & 421 & 141 & Tyler & 2 & 9 & 0 \\
Lewis & 8 & 9 & 3 & Upshur & 9 & 14 & 2 \\
Lincoln & 32 & 49 & 17 & Wayne & 27 & 67 & 34 \\
Logan & 56 & 57 & 26 & Webster & 2 & 6 & 7 \\
Marion & 31 & 40 & 19 & Wetzel & 9 & 7 & 6 \\
Marshall & 14 & 17 & 6 & Wirt & 2 & 1 & 4 \\
Mason & 28 & 49 & 13 & Wood & 44 & 111 & 32 \\
McDowell & 18 & 50 & 6 & Wyoming & 31 & 27 & 7 \\
Mercer & 77 & 130 & 42 & TOTAL & & $\mathbf{5 , 0 7 9}$ & \\
\hline
\end{tabular}

${ }^{\mathrm{I}}$ Totals may not sum to 5,082 as a result of missing data. 
Figure 2: Map of total number of WV Medicaid beneficiaries who inject drugs by county, 2015

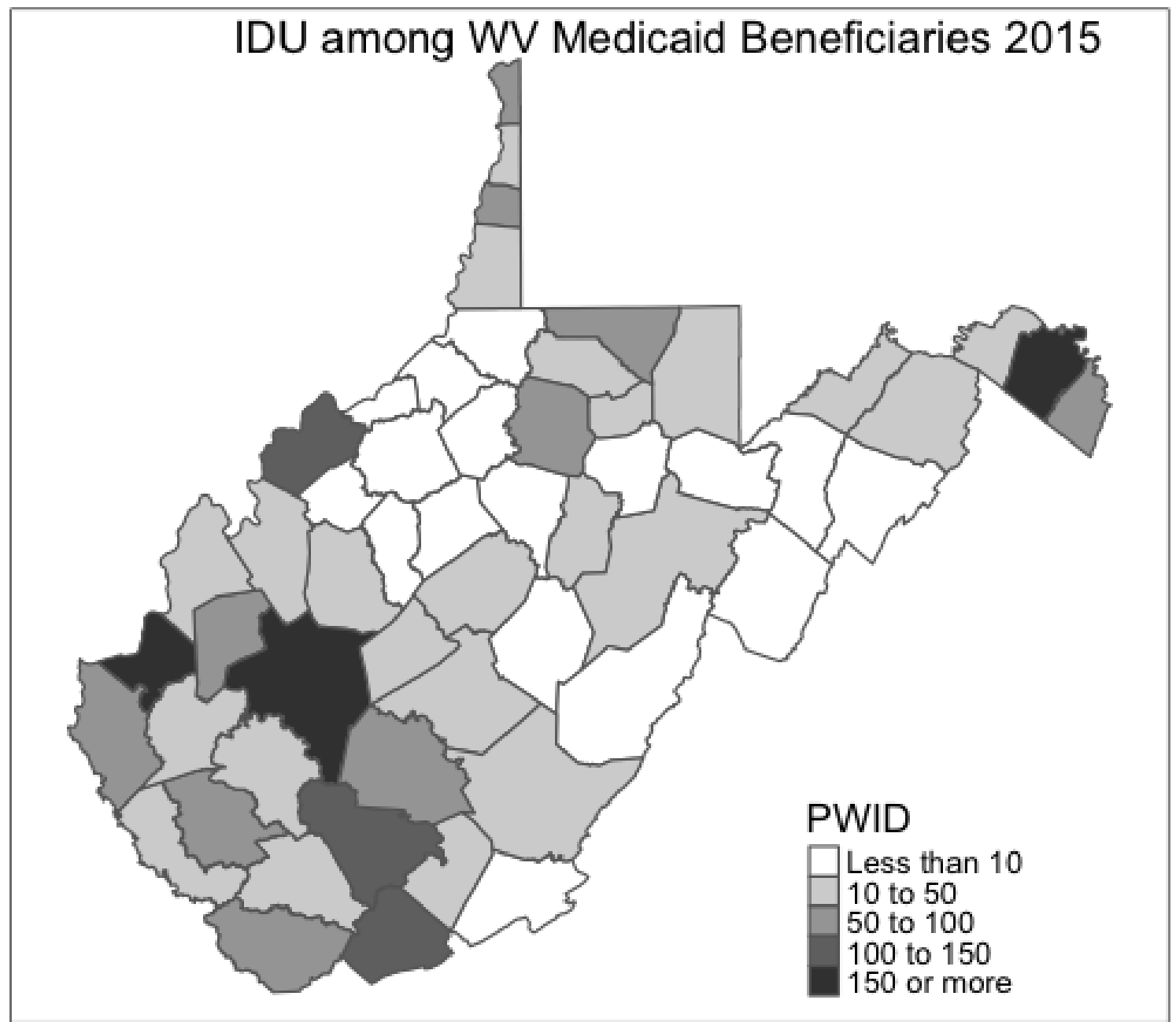

The most common types of services accessed and patient diagnoses can be seen in Tables 6 and 7. 'Physician Non-Specialty Inpatient' services had the most patient visits with 2,957 over the study period, followed by 'Facility Inpatient Medical' ( $n=2,783)$, 'Facility Outpatient ER' $(n=2,099)$, and 'Physician Non-Specialty ER' $(n=1,315)$. The most common diagnoses within this sample included 'Toxic Effects of Substances' $(n=5,077)$, 'Infections of the Skin or Subcutaneous Tissue' ( $\mathrm{n}=4,127)$, 'Mental Health- Substance Abuse' $(\mathrm{n}=2,030)$, and 'Hepatitis, Viral' $(n=1,302)$. 
Table 6: Ten most common service categories by number of patient visits among WV Medicaid beneficiaries who inject drugs, 2014 - 2016

\begin{tabular}{l|l}
\hline Service Category & Patient Visits \\
\hline Physician Non-Specialty Inpatient & 2,957 \\
Facility Inpatient Medical & 2,783 \\
Facility Outpatient ER & 2,099 \\
Physician Non-Specialty ER & 1,315 \\
Substance Abuse Other Outpatient & 772 \\
Physician Non-Specialty Office & 505 \\
Visits & 499 \\
Physician Specialty ER & 482 \\
Substance Abuse Office Visits & 433 \\
Professional Diagnostic Services & 422 \\
Laboratory Outpatient Other & $\mathbf{1 2 , 2 6 7}$ \\
\hline Total &
\end{tabular}

Table 7: Ten most common diagnoses among WV Medicaid beneficiaries who inject drugs, 2014 - 2016.

\begin{tabular}{l|r}
\hline Diagnoses & n \\
\hline Toxic Effects of Substances & 5,077 \\
Infections/Inflammation - Skin/Subcutaneous & 4,127 \\
Tissue & 2,141 \\
Infections, NEC & 2,030 \\
Mental Health - Substance Abuse & 1,302 \\
Hepatitis, Viral & 735 \\
Cardiovascular Disorder, NEC & 561 \\
Pregnancy without Delivery & 520 \\
Signs/Symptoms/Other Cond, NEC & 457 \\
Infections - Musculoskeletal & 432 \\
Mental Health - Depression & $\mathbf{1 7 , 3 8 2}$ \\
\hline Total & \\
\hline
\end{tabular}

\subsection{Specific Aim Results}

\subsubsection{Specific Aim 1}

Aim 1: Determine the efficacy of state Medicaid data as a proxy for disease surveillance data in estimating the number of drug overdoses and injection drug related infections in WV between 2014 and 2016. 
Rates per 100,000 people for all Medicaid beneficiaries are compared to state surveillance reported rates in Table 8. According to Medicaid claims data, 739 beneficiaries had an acute HCV diagnosis, 420 had an acute HBV diagnosis, 229 had an HIV/AIDS diagnosis, and 835 had a heroin poisoning in 2015. The year 2015 was used for these comparisons since it is the only year within the data that includes an entire calendar year. The denominator for the incidence rates among Medicaid beneficiaries was defined based on the estimate that Medicaid covers approximately $29 \%$ of WV. (Foundation, 2017) For each rate (e.g. acute HCV, acute HBV, HIV, and heroin OD), Medicaid claims data were significantly different from state surveillance data at the alpha level of 0.05 .

Table 8: Injection drug use (IDU) related diagnoses among all WV Medicaid beneficiaries in 2015 compared to incidence reported by surveillance data.

\begin{tabular}{|c|c|c|c|c|c|}
\hline \multirow[b]{2}{*}{ Diagnosis } & \multicolumn{2}{|c|}{ Medicaid Beneficiaries } & \multicolumn{2}{|c|}{ State Surveillance ${ }^{2}$} & \multirow{2}{*}{$\begin{array}{c}\text { Test for } \\
\text { Equivalence }^{4} \\
\text { p-value }(95 \% \text { CI })^{3}\end{array}$} \\
\hline & n & $\begin{array}{l}\text { Rate per } \\
100,000^{1}\end{array}$ & $\mathbf{n}$ & $\begin{array}{l}\text { Rate per } \\
100,000\end{array}$ & \\
\hline Hepatitis C, acute & 739 & 138.2 & 63 & 3.4 & $\begin{array}{l}<0.001(124.7, \\
144.8)\end{array}$ \\
\hline Hepatitis B, acute & 420 & 78.5 & 272 & 14.7 & $<0.001(56.0,71.6)$ \\
\hline $\begin{array}{l}\text { Persons living with } \\
\text { HIV/AIDS }\end{array}$ & 229 & 42.8 & 1,988 & 107.8 & $<0.001(57.6,72.4)$ \\
\hline Heroin Poisoning & 838 & 156.1 & 327 & 17.7 & $\begin{array}{l}<0.001 \text { (127.5, } \\
149.3)\end{array}$ \\
\hline
\end{tabular}

${ }^{\mathrm{I}}$ Denominator $(534,760)$ equals $29 \%$ of West Virginians covered by Medicaid x 2015 population $(1,844,000)$.

${ }^{2}$ Sources: West Virginia Department of Health and Human Resources; WV Poison Center Annual Report

${ }^{3} 95 \%$ Confidence intervals are multiplied by 100,000 for interpretations

${ }^{4} \mathrm{P}$-value $<0.05$ implies there is significant difference in the comparison

\subsubsection{Specific Aim 2}

Aim 2: Examine service utilization and characteristics of WV Medicaid beneficiaries who inject drugs between 2014 and 2016. 
Service utilization was described according to specific types of services, including inpatient, mental health/substance abuse, and emergency room services.

\section{Inpatient Services}

Table 9 outlines characteristics of WV Medicaid beneficiaries who received an inpatient service during the study period. Between 2014 and 2016, this sample of WV Medicaid beneficiaries had 6,280 inpatient services. Among those who had an inpatient related service, most were white $(\mathrm{n}=1,478 ; 61.3 \%)$ men $(\mathrm{n}=1,251 ; 51.9 \%)$, with a median age of 36 years. Unknown race was frequently reported for this sample $(n=776 ; 32.2 \%)$. The most common clinical conditions were related to infections $(n=2,889)$, and particularly soft tissue infections $(n=1,481)$. Toxic effects of substances were also a frequently reported clinical condition ( $n=689)$.

Most individuals with an inpatient service accessed one service during the study period $(\mathrm{n}=1,354 ; 56.2 \%)$, while $401(16.6 \%)$ had two, and $648(26.9 \%)$ had three or more. Table 10 shows the adjusted associations between WV Medicaid beneficiary characteristics and the frequency of inpatient service utilization obtained from an ordinal logistic regression model. Individuals with endocarditis $(\mathrm{aOR}=2.06,95 \% \mathrm{CI}=[1.58,2.70])$ and soft tissue infections $(\mathrm{aOR}=1.71,95 \% \mathrm{CI}=[1.42,2.07])$ had higher odds of utilizing more inpatient services compared to those who did not. Acute HCV infection had a protective effect on having more inpatient services $(\mathrm{aOR}=0.59,95 \% \mathrm{CI}=[0.39,0.88])$. 
Table 9: Characteristics of WV Medicaid beneficiaries who received an inpatient service between 2014 and $2016(n=2,411)$.

\begin{tabular}{|c|c|}
\hline Characteristic & $n(\%)^{1}$ \\
\hline Total Number of Inpatient Visits & 6,280 \\
\hline \multicolumn{2}{|l|}{ Gender } \\
\hline Men & $1,251(51.9)$ \\
\hline Women & $1,159(48.1)$ \\
\hline \multicolumn{2}{|l|}{ Race } \\
\hline African American & $57(2.4)$ \\
\hline Other $^{3}$ & $99(4.1)$ \\
\hline White & $1,478(61.3)$ \\
\hline Unknown & $776(32.2)$ \\
\hline \multicolumn{2}{|l|}{ Clinical Condition $^{2}$} \\
\hline Skin/Subcutaneous Tissue Infection & 1,481 \\
\hline Other Infections & 1,408 \\
\hline Toxic Effect of Substances & 689 \\
\hline Cardiovascular Disorder & 401 \\
\hline Viral Hepatitis & 231 \\
\hline \multicolumn{2}{|l|}{ District } \\
\hline District 1 & 334 (13.9) \\
\hline District 2 & $521(21.6)$ \\
\hline District 3 & $536(22.2)$ \\
\hline District 4 & $164(6.8)$ \\
\hline District 5 & $146(6.1)$ \\
\hline District 6 & $145(6.0)$ \\
\hline District 7 & $295(12.2)$ \\
\hline \multirow[t]{2}{*}{ District 8} & $269(11.2)$ \\
\hline & Median (min - max) \\
\hline Age (years) & $36(18-85)$ \\
\hline Number of Encounters per Person & $1(1-62)$ \\
\hline
\end{tabular}

${ }^{\mathrm{I}}$ Totals may not add to $100 \%$ due to missing data

${ }^{2}$ Clinical conditions based on duplicated dataset.

${ }^{3}$ Other race defined as Hispanic or American Indian/Alaska Native 
Table 10: Adjusted associations between WV Medicaid beneficiary characteristics and inpatient service utilization between 2014 and 2016.

\begin{tabular}{l|l}
\hline Characteristic & aOR $(95 \%$ CI $)$ \\
\hline Endocarditis Infection & Reference \\
No & $2.06(1.58,2.70)$ \\
Yes & \\
\hline Soft Tissue Infection & Reference \\
No & $1.71(1.42,2.07)$ \\
Yes & \\
\hline Acute Hepatitis C Infection & Reference \\
No & $0.59(0.39,0.88)$ \\
Yes & $0.98(0.97,0.99)$ \\
\hline Age & \\
\hline
\end{tabular}

\section{Emergency Room Services}

Table 11 summarizes the characteristics of WV Medicaid beneficiaries who inject drugs and received an emergency room (ER) service during the study period. Most of these individuals were white $(n=1,290 ; 59.8 \%)$ men $(n=1,159 ; 53.7 \%)$, with a median age of 33 . The predominant clinical condition was drug poisoning $(n=2,280)$. Soft tissue infections were the next most frequent $(n=949)$, followed by other infections $(n=113)$, viral hepatitis $(n=59)$ and respiratory disorders $(n=58)$.

Among WV Medicaid beneficiaries who inject drugs and received an ER service, most received one or two services during the study period $(\mathrm{n}=1,790 ; 83.0 \%), 327(15.2 \%)$ received three to five services, and $40(1.9 \%)$ received six or more services. Table 12 contains the adjusted relationships between patient characteristics and the frequency of ER service utilization. Individuals with endocarditis $(\mathrm{aOR}=2.60,95 \% \mathrm{CI}=[1.20,5.26])$, soft-tissue infections $(\mathrm{aOR}=$ $2.17,95 \% \mathrm{CI}=[1.48,3.23])$, or had a drug poisoning $(\mathrm{aOR}=2.29,95 \% \mathrm{CI}=[1.62,3.31]) \mathrm{had} \mathrm{a}$ higher odds of presenting for more ER services compared to those who did not. 
Table 11: Characteristics of WV Medicaid beneficiaries who received an emergency room (ER) service between 2014 and $2016(n=2,157)$.

\begin{tabular}{l|l}
\hline Characteristic & $\mathbf{n}(\boldsymbol{\%})$ \\
\hline Total Number of ER Visits & 3,913 \\
\hline Gender & $1,159(53.7)$ \\
Men & $996(46.2)$ \\
Women & \\
\hline Race & $45(2.1)$ \\
African American & $122(5.7)$ \\
Other & $1,290(59.8)$ \\
White & $700(32.5)$ \\
Unknown & \\
\hline Clinical Condition ${ }^{2}$ & 2,280 \\
Toxic Effect of Substances & 949 \\
Skin/Subcutaneous Tissue Infection & 113 \\
Other Infections & 59 \\
Viral Hepatitis & 58 \\
Respiratory Disorder & \\
\hline District & $216(10.0)$ \\
District 1 & $620(28.7)$ \\
District 2 & $462(21.4)$ \\
District 3 & $69(3.2)$ \\
District 4 & $133(6.2)$ \\
District 5 & $144(6.7)$ \\
District 6 & $198(9.2)$ \\
District 7 & $311(14.4)$ \\
District 8 & Median (min - max) \\
\hline & $33(18-78)$ \\
\hline Age (years) & $1(1-13)$ \\
\hline Number of Encounters per Person & \\
\hline & \\
\hline Totals may not add to & \\
\hline & \\
\hline
\end{tabular}

${ }^{\mathrm{I}}$ Totals may not add to $100 \%$ due to missing data

${ }^{2}$ Clinical conditions based on duplicated dataset.

${ }^{3}$ Other race defined as Hispanic or American Indian/Alaska Native 
Table 12: Adjusted associations between WV Medicaid beneficiary characteristics and emergency room (ER) service utilization between 2014 and 2016.

\begin{tabular}{l|l}
\hline Characteristic & aOR $(\mathbf{9 5} \% \mathbf{C I})$ \\
\hline Endocarditis Infection & Reference \\
No & $2.60(1.20,5.26)$ \\
Yes & \\
\hline Drug Poisoning & Reference \\
No & $2.29(1.62,3.31)$ \\
Yes & \\
\hline Soft Tissue Infection & Reference \\
No & $2.17(1.48,3.23)$ \\
Yes & \\
\hline
\end{tabular}

\section{Mental Health and Substance Abuse Services}

Table 13 highlights characteristics of WV Medicaid beneficiaries who inject drugs that utilized mental health or substance abuse services between 2014 and 2016 . White $(n=488$; $60.0 \%)$ men $(n=413 ; 50.8 \%)$ had the most mental health or substance abuse services throughout the study period. The median age for these individuals was 34 years. Substance abuse $(n=1,572)$, depression $(n=262)$, bipolar disorder $(n=109)$, other psychoses $(n=53)$ and anxiety disorder $(n=42)$ were the most frequently reported clinical conditions.

The majority of individuals who utilized mental health or substance abuse services had one or two service encounters during the study period ( $\mathrm{n}=649 ; 80 \%)$. Comparatively, $119(15 \%)$ had three to five encounters, and $45(6 \%)$ had six or more encounters. Unadjusted and adjusted associations between patient characteristics and mental health and substance abuse service usage were explored, but no statistically significant relationships were found at the 0.05 alpha level. 
Table 13: Characteristics of WV Medicaid beneficiaries who received a mental health and/or substance abuse service between 2014 and $2016(n=813)$.

\begin{tabular}{l|l}
\hline Characteristic & $\mathbf{n}(\boldsymbol{\%})^{\mathbf{1}}$ \\
\hline Total Number of Visits & 2,111 \\
\hline Gender & $413(50.8)$ \\
Men & $399(49.1)$ \\
Women & \\
\hline Race & $6(1.0)$ \\
African American & $63(7.7)$ \\
Other & $488(60.0)$ \\
White & $255(31.4)$ \\
Unknown & \\
\hline Clinical Condition ${ }^{2}$ & 1,572 \\
Mental Health - Substance Abuse & 262 \\
Mental Health - Depression & 109 \\
Mental Health - Bipolar Disorder & 53 \\
Mental Health - Psychoses & 42 \\
Mental Health - Anxiety Disorder & \\
\hline District & $171(21.0)$ \\
District 1 & $189(23.2)$ \\
District 2 & $138(17.0)$ \\
District 3 & $37(4.6)$ \\
District 4 & $48(5.9)$ \\
District 5 & $61(7.5)$ \\
District 6 & $71(8.7)$ \\
District 7 & $97(11.9)$ \\
District 8 & Median (min - max) \\
\hline & $34(18-65)$ \\
\hline Age (years) & $1(1-65)$ \\
\hline Number of Encounters & \\
\hline Totals may not add 100\% due to \\
\hline
\end{tabular}

${ }^{\mathrm{I}}$ Totals may not add to $100 \%$ due to missing data

${ }^{2}$ Clinical conditions based on duplicated dataset.

${ }^{3}$ Other race defined as Hispanic or American Indian/Alaska Native 


\subsubsection{Specific Aim 3}

Aim 3: Examine the cost of service utilization of WV Medicaid beneficiaries who inject drugs between 2014 and 2016.

The total cost of medical services for this sample was $\$ 18,473,217$, and the total cost for prescriptions was $\$ 154,789,571$. The most commonly accessed services for this sample and the associated costs are listed in Table 14. Inpatient services incurred the highest cost for this sample during the study period. Specifically, 'Facility Inpatient Medical' services accounted for $\$ 14,390,988.00$, nearly 18 times costlier than the next highest service type (Mental Health Inpatient; \$805,993.30). 'Facility Outpatient ER' (\$779,515.90), 'Facility Inpatient Long Term Care' $(\$ 656,044.90)$, and 'Substance Abuse Inpatient' $(\$ 420,346.50)$ also accounted for a large proportion of the total costs for this sample.

Results from the multiple regression models are shown in Tables 15 and 16. In the first model, where the outcome was the natural log of the cost for medical services, while controlling for other covariates, men cost $16 \%$ more than women; individuals with endocarditis cost $18 \%$ more than those without; individuals with acute $\mathrm{HCV}$ infection cost $16 \%$ more than those without; individuals with acute HBV infection cost 53\% more than those without; and individuals residing in District 5 cost $84 \%$ more than those living in District 3 (reference). The second model, in which the outcome was the natural log of the total cost of medical services and prescription drugs per person, men cost less than women (24.6\% decrease), while those with HIV (281\% increase) and endocarditis (48.5\% increase) cost more than those not infected. 
Table 14: Commonly accessed services among WV Medicaid beneficiaries who inject drugs and associated costs (2014-2016).

\begin{tabular}{l|l|l}
\hline Service Type & Visits $(\mathbf{n})$ & Total Cost \\
\hline Facility Inpatient Long Term Care & 105 & $\$ 656,044.90$ \\
Facility Inpatient Maternity & 108 & $\$ 241,074.40$ \\
Facility Inpatient Medical & 2,783 & $\mathbf{\$ 1 4 , 3 9 0 , 9 8 8 . 0 0}$ \\
Facility Inpatient Non Acute & 8 & $\$ 10,746.44$ \\
Physician Specialty Inpatient & 319 & $\$ 38,169.89$ \\
Physician Non-Specialty Inpatient & 2,957 & $\mathbf{\$ 4 3 6 , 4 2 6 . 6 0}$ \\
\hline Inpatient Total & $\mathbf{6 , 2 8 0}$ & $\mathbf{\$ 1 5 , 7 7 3 , 4 5 0 . 2 3}$ \\
\hline Facility Outpatient ER & 2,099 & $\mathbf{\$ 7 7 9 , 5 1 5 . 9 0}$ \\
Physician Non-Specialty ER & 1,315 & $\mathbf{\$ 1 3 0 , 1 4 0 . 3 0}$ \\
Physician Specialty ER & 499 & $\mathbf{\$ 5 9 , 8 3 3 . 3 0}$ \\
\hline Emergency Room Total & $\mathbf{3 , 9 1 3}$ & $\mathbf{\$ 9 6 9 , 4 8 9 . 5 0}$ \\
\hline Mental Health Inpatient & 335 & $\mathbf{\$ 8 0 5 , 9 9 3 . 3 0}$ \\
Mental Health Office Visits & 68 & $\mathbf{\$ 4 , 3 7 5 . 7 1}$ \\
Mental Health Other Outpatient & 136 & $\mathbf{\$ 2 4 , 8 4 5 . 6 7}$ \\
\hline Mental Health Total & $\mathbf{5 3 9}$ & $\mathbf{\$ 8 3 5 , 2 1 4 . 6 8}$ \\
\hline Substance Abuse Inpatient & 318 & $\mathbf{\$ 4 2 0 , 3 4 6 . 5 0}$ \\
Substance Abuse Office Visits & 482 & $\mathbf{\$ 2 7 , 4 2 8 . 3 9}$ \\
Substance Abuse Other Outpatient & 772 & $\mathbf{\$ 7 4 , 8 0 9 . 8 6}$ \\
\hline Substance Abuse Total & $\mathbf{1 , 5 7 2}$ & $\mathbf{\$ 5 2 2 , 5 8 4 . 7 5}$ \\
\hline TOTAL & $\mathbf{1 2 , 3 0 4}$ & $\mathbf{\$ 1 8 , 1 0 0 , 7 3 9 . 1 6}$ \\
\hline
\end{tabular}

${ }^{1}$ Not including Mental Health or Substance Abuse Inpatient services. 
Table 15: Relationships between characteristics of WV Medicaid beneficiaries who inject drugs and the natural log of total cost per medical service encounter (US Dollars).

\begin{tabular}{|c|c|c|}
\hline Characteristic & $\begin{array}{l}\text { Coefficient (95\% } \\
\text { CI) }\end{array}$ & $\begin{array}{l}\text { \% Change vs. } \\
\text { Reference }\end{array}$ \\
\hline $\begin{array}{l}\text { Service Type } \\
\text { Inpatient } \\
\text { Emergency } \\
\text { Mental/Substance Abuse } \\
\text { Other }\end{array}$ & $\begin{array}{c}\text { Reference } \\
-1.12(-1.20,-1.05) \\
-1.30(-1.39,1.20) \\
-2.39(-2.47,-2.31)\end{array}$ & $\begin{array}{c}\text { Reference } \\
-67.5 \% \\
-72.6 \% \\
-90.8 \% \\
\end{array}$ \\
\hline Age (years) & $0.01(0.01,0.02)$ & $1.5 \%$ \\
\hline $\begin{array}{l}\text { Gender } \\
\text { Women } \\
\text { Men }\end{array}$ & $\begin{array}{c}\text { Reference } \\
0.15(0.10,0.21)\end{array}$ & $\begin{array}{c}\text { Reference } \\
16.9 \%\end{array}$ \\
\hline $\begin{array}{l}\text { Race } \\
\text { White } \\
\text { Black } \\
\text { Other }^{1} \\
\text { Unknown }\end{array}$ & $\begin{array}{c}\text { Reference } \\
-0.16(-0.36,0.03) \\
-0.13(-0.25,0.00) \\
-0.11(-0.17,-0.04)\end{array}$ & $\begin{array}{l}\text { Reference } \\
-15.2 \% \\
-12.0 \% \\
-10.1 \%\end{array}$ \\
\hline $\begin{array}{l}\text { District } \\
\text { District } 3 \\
\text { District } 1 \\
\text { District } 2 \\
\text { District } 4 \\
\text { District } 5 \\
\text { District } 6 \\
\text { District } 7 \\
\text { District } 8 \\
\end{array}$ & $\begin{array}{c}\text { Reference } \\
0.29(0.19,0.38) \\
0.19(0.11,0.28) \\
0.27(0.13,0.41) \\
0.610 .48,0.75) \\
0.50(0.37,0.63) \\
0.31(0.21,0.41) \\
0.19(0.09,0.29)\end{array}$ & $\begin{array}{c}\text { Reference } \\
33.2 \% \\
21.3 \% \\
30.7 \% \\
84.7 \% \\
65.2 \% \\
36.4 \% \\
21.3 \%\end{array}$ \\
\hline $\begin{array}{l}\text { Endocarditis Infection } \\
\text { No } \\
\text { Yes }\end{array}$ & $\begin{array}{c}\text { Reference } \\
0.17(0.06,0.27)\end{array}$ & $\begin{array}{c}\text { Reference } \\
18.1 \%\end{array}$ \\
\hline $\begin{array}{l}\text { Acute HBV Infection } \\
\text { No } \\
\text { Yes }\end{array}$ & $\begin{array}{c}\text { Reference } \\
0.53(0.39,0.66)\end{array}$ & $\begin{array}{c}\text { Reference } \\
69.0 \%\end{array}$ \\
\hline
\end{tabular}

Adjusted $\mathbf{R}^{2}=\mathbf{0 . 2 3 7 9}$

${ }^{1}$ Other race defined as Hispanic and American Indian/Alaska Native 
Table 16: Relationships between characteristics of WV Medicaid beneficiaries who inject drugs and the natural log of the combined total cost of medical services and prescription drugs per person (US Dollars).

\begin{tabular}{l|c|c}
\hline Characteristic & $\begin{array}{l}\text { Coefficient (95\% } \\
\text { CI) }\end{array}$ & $\begin{array}{l}\text { \% Change vs. } \\
\text { Reference }\end{array}$ \\
\hline Service Type & Reference \\
Inpatient & Reference & $-68.1 \%$ \\
Emergency & $-1.14(-1.27,-1.01)$ & $-19.6 \%$ \\
Mental/Substance Abuse & $-0.22(-0.38,-0.05)$ & $-53.8 \%$ \\
Other & $-0.77(-0.92,-0.63)$ & $3.1 \%$ \\
\hline Age (years) & $0.03(0.02,0.04)$ & \\
\hline Gender & Reference & Reference \\
Women & $-0.28(-0.39,-0.18)$ & $-24.6 \%$ \\
Men & Reference & Reference \\
\hline Endocarditis Infection & $0.40(0.16,0.63)$ & $48.5 \%$ \\
No & Reference & Reference \\
Yes & $1.34(0.98,1.69)$ & $281.0 \%$ \\
\hline HIV Infection & \multicolumn{2}{|}{} \\
No & \multicolumn{2}{|l}{} \\
Yes & Adjusted $\mathbf{R}^{2}=\mathbf{0 . 1 8 6 1}$ \\
\hline
\end{tabular}




\section{CHA P TER 5: DIS CUSSION}

This dissertation had three primary aims. The first aim was to determine the efficacy of state Medicaid data as a proxy for disease surveillance data in estimating the number of drug overdoses and injection drug related infections in WV between 2014 and 2016. The prevalence rates for $\mathrm{HIV}$, acute $\mathrm{HCV}$, acute $\mathrm{HBV}$, and heroin overdoses (OD) according to West Virginia (WV) Medicaid claims data are reported in Table 8. Each prevalence rate was significantly different from state surveillance rates at the alpha level of 0.05. This result indicates that ICD codes from a Medicaid claims database are not a suitable proxy for state surveillance. The likely reason for the large discrepancy between these data sources with regards to acute $\mathrm{HCV}$, acute $\mathrm{HBV}$, and HIV is the inability to determine whether the case is new with ICD codes. Consequently, the prevalence rates as determined by Medicaid claims data were likely overestimations. As for heroin ODs, the Poison Control Center monitors OD rates that are reported to it passively. However, reporting heroin ODs is not mandated in WV, as it is with new cases of acute HCV, acute HBV, and HIV. Therefore, it is possible that the heroin OD prevalence rate from the Poison Control Center is an underestimation of the true rate. Similarly, the heroin OD rate from Medicaid claims data is also possibly underestimating the prevalence since not every person who injects drugs (PWID) is insured by Medicaid. (Tookes et al., 2015)

The second aim of this dissertation project was to describe service utilization among WV Medicaid beneficiaries who inject drugs. Three service types were specifically investigated for this project, including inpatient, emergency room (ER), and mental health and substance abuse services. 
Of the service types, inpatient services were the most frequently utilized with 2,411 people accumulating 6,280 visits between July 2014 and June 2016. The southern part of WV, including Districts 1 (13.9\%), 2 (21.6\%), and $3(22.2 \%)$ had the most individuals accessing inpatient services. Comparable numbers of men (51.9\%) and women (48.1\%) utilized inpatient services, while white race $(61.3 \%)$ was the most frequently reported. Infectious diseases, including soft tissue infections $(n=1,481)$ and viral hepatitis $(n=231)$, were the most common conditions reported among those receiving inpatient services. When examining adjusted relationships between patient characteristics and frequency of service utilization obtained via ordinal logistic regression, infectious diseases again were consequential. Specifically, those with endocarditis infection had a 2.06 times higher odds of receiving three or more inpatient services during the study period compared to receiving two services or less. Similarly, individuals with a soft tissue infection had a 1.71 times higher odds of receiving three or more inpatient services. Infectious diseases, like endocarditis and soft tissue infections, are largely preventable through the use of clean injecting equipment. Harm reduction strategies, like syringe exchange programs (SEPs), have proven to be effective in reducing the incidence of these types of infectious diseases by supplying clean injection equipment and other services. (Bastos \& Strathdee, 2000; Kwon et al., 2009; Moss \& Munt, 2003; Vickerman et al., 2006; D. P. Wilson et al., 2015) Reducing soft tissue and endocarditis infections, among others, could possibly reduce the use of inpatient services, which are generally associated with higher costs. (Tookes et al., 2015)

ER services were the second most commonly accessed service type for this sample, with 2,157 people presenting to the ER 3,913 times during the study period. There were slightly more men $(53.7 \%)$ than women $(46.2 \%)$, and white race $(59.8 \%)$ was the most commonly reported among those accessing ER services. Similar to inpatient services, the southern Districts 2 
(28.7\%) and $3(21.4 \%)$ had the largest number of individuals utilizing the ER. Similar to previous studies, drug poisonings $(n=2,280)$ accounted for the largest proportion of ER services accessed, and were 2.4 times more frequent than the next clinical condition (soft tissue infections; n=949). (Backmund, Schuetz, Meyer, Edlin, \& Reimer, 2009) Adjusted associations further showed that drug poisonings were associated with more frequent ER usage. Individuals with a drug poisoning had a 2.29 times higher odds of having six or more ER services compared to three to five services, and one to two services. Similar to inpatient services, endocarditis $(\mathrm{aOR}=2.60)$ and soft tissue infections $(\mathrm{aOR}=2.17)$ were also associated with more ER service usage. This study is in agreement with previous studies show that PWID tend to use the ER frequently. (Fairbairn et al., 2012; Palepu et al., 2001) As with inpatient services, infectious diseases were a large component of frequent ER service utilization within this sample. Increasing access to preventative care for PWID may serve to reduce frequent service utilization, and thereby reduce cost.

Mental health and substance abuse services were accessed 2,111 times by $813 \mathrm{WV}$ Medicaid beneficiaries who inject drugs during the study period. Approximately equal numbers of men (50.8\%) and women (49.1\%) utilized mental health and substance abuse services, while white race $(60.0 \%)$ outweighed all others. As with inpatient and ER services, the southern districts, including $1(21.0 \%), 2(23.2 \%)$, and $3(17.0 \%)$, had the most individuals accessing mental health and substance abuse services. Mental health conditions relating to substance abuse $(n=1,572)$, depression $(n=262)$ and bipolar disorder $(n=109)$ were the most commonly reported. Adjusted relationships between patient characteristics and frequency of mental health and substance abuse service usage were explored, but yielded no statistically significant relationships at the alpha level of 0.05 . 
The third aim of this dissertation project was to describe the cost of service utilization among WV Medicaid beneficiaries who inject drugs. The total cost for medical services and prescription drugs was $\$ 18,473,217$ and $\$ 154,789,571$, respectively. Similar to Aim 2, cost was described according to inpatient, ER, and mental health and substance abuse services. Congruent with current literature, inpatient services were the costliest. (Tookes et al., 2015) A total of 6,280 inpatient services during the study period accumulated $\$ 15,773,450.23$ in charges. In other words, inpatient services, not including mental health or substance abuse inpatient services, accounted for $87 \%$ of the total cost for medical services accessed by this sample $(\$ 18,473,217)$ during the entire study period. Also, mental health specific services had far fewer visits than any other service type, yet cost a similar amount compared to ER and substance abuse services.

Two separate multiple regression models were constructed to examine the relationship between patient characteristics and cost. The first included the natural log of cost for medical services only, and the second included the natural log of cost for medical services and prescription drugs. In the first model (medical costs only), while controlling for other covariates, inpatient services were shown to cost significantly more than any other service type. Also, every district cost significantly more than District 3 (reference). District 3 was chosen as the reference because is the most populated area of WV. Infectious diseases, e.g. endocarditis $(18.1 \%$ increase), and acute HBV infection (69.0\% increase), were also associated with higher service costs. In the second model (medical and prescription costs), HIV infection was associated with significantly large increase in cost. Individuals with HIV cost $281 \%$ more than their counterparts. These results further support the need to increase access of preventative services, like SEPs and vaccinations, to reduce morbidity and cost within the injection drug use (IDU) population. As mentioned, many common infections among PWID are preventable given access and subsequent 
utilization of these services, and the cost of providing such services is cost effective. Further, while HIV infection is associated with multiple risk behaviors other than IDU, SEPs can serve to reduce HIV risk among PWID. (D. P. Wilson et al., 2015) Model fit was assessed via diagnostic plots, e.g. Q-Q normality plots and residuals plots, and it was determined that no major assumption violations occurred. The adjusted $\mathrm{R}^{2}$ for the first model was 0.2379 and 0.1861 for the second.

\subsection{Limitations}

The goal of this dissertation project was to determine specific service utilization and associated costs, describe health outcomes, and develop a comprehensive profile of PWID in WV using statewide, individual service-level data. Few, if any studies, have investigated IDU at the state level using this methodology. However, there were limitations to this project.

First, Medicaid claims data come from an administrative database, and are not directly intended for research. Consequently, some variables did not contain an ideal level of information, or had missing information. For instance, nearly 33\% of individuals in this dataset had an 'unknown' race reported. This likely affected the estimates obtained from various models, and thus limited the interpretations. Also, this project's methodology hinged on the use of ICD codes to identify IDU and associated conditions. This is a limitation for various reasons, including the tendency for ICD codes to underestimate prevalence of certain conditions. (G. Jones et al., 2012) Also, while the framework for identifying IDU was based on a previous study (Tookes et al., 2015), it is possible that misclassification on case status (IDU) occurred since it is not possible to directly identify IDU with ICD codes. The study period for this project also overlapped with the transition between ICD-9 and ICD-10 codes. While both were included in the analysis, the cross-walk between revisions may not be $100 \%$ 
This study is also limited in that the project sample only included those who were insured by Medicaid. Although Medicaid is the largest insurer for WV, and studies report that a large number of PWID are covered by Medicaid, this study has limited generalizability outside of the WV IDU Medicaid population. (Foundation, 2017; Takahashi et al., 2010; Tookes et al., 2015) In addition, many PWID do not have insurance coverage, and possibly have different characteristics compared to those who are insured.

For Specific Aim 2, ordinal logistic regression was used to determine relationships between patient characteristics and frequent service usage. One of the underlying assumptions for this type of model is the proportional odds assumption, or that the relationship between a predictor and each level of the outcome variable are the same. Assessment of this assumption showed that some variables were questionable, while others were appropriate. Violation of this assumption would indicate that the effect of a variable is different according each level of the outcome. This may warrant a different model, e.g. partial proportional odds model, which relaxes the proportional odds assumption.

\subsection{Future Research}

Results from this project warrant further research. Given the results from Aim 1, procedure codes, which identify specific surgical, medical, or diagnostic activities, may provide more information to help identify new cases of acute $\mathrm{HCV}$, acute $\mathrm{HBV}$, and HIV in administrative databases. If effective in identifying new cases, administrative data could provide information on individuals who cross state lines for medical care, and in turn improve surveillance for these conditions. 
Different statistical models for investigating the relationship between patient characteristics and frequency of service utilization (Aim 2) are recommended. The partial proportional odds model relaxes the limiting proportional odds assumption, but complicates interpretations. Another method may be to treat frequency of service utilization as a count variable, and employee negative binomial regression to explore relationships.

Medicaid data was used for this project because it is the largest insurer of WV and is reportedly one of the largest insurers of PWID. However, generalizability to PWID who are not covered by Medicaid is limited. Therefore, other data sources may be considered. Hospital discharge data, for example, provide an array of information, including diagnosis codes, procedure codes, cost, and demographics. Additionally, hospital discharge data includes information on all-payer types. Using hospital discharge data may serve to improve external validity. 


\section{References}

Algren, D. A., Monteilh, C. P., Punja, M., Schier, J. G., Belson, M., Hepler, B. R., . . Rubin, C. (2013). Fentanyl-associated fatalities among illicit drug users in Wayne County, Michigan (July 2005-May 2006). J Med Toxicol, 9(1), 106-115. doi:10.1007/s13181-0120285-4

Allen, S. T., Ruiz, M. S., \& Jones, J. (2016). Assessing Syringe Exchange Program Access among Persons Who Inject Drugs (PWID) in the District of Columbia. Journal of Urban Health-Bulletin of the New York Academy of Medicine, 93(1), 131-140. doi:10.1007/s11524-015-0018-5

Alter, M. J., \& Moyer, L. A. (1998). The importance of preventing hepatitis C virus infection among injection drug users in the United States. J Acquir Immune Defic Syndr Hum Retrovirol, 18 Suppl 1, S6-10.

Altice, F. L., Kamarulzaman, A., Soriano, V. V., Schechter, M., \& Friedland, G. H. (2010). Treatment of medical, psychiatric, and substance-use comorbidities in people infected with HIV who use drugs. Lancet, 376(9738), 367-387. doi:10.1016/S01406736(10)60829-X

Atlani, L., Carael, M., Brunet, J. B., Frasca, T., \& Chaika, N. (2000). Social change and HIV in the former USSR: the making of a new epidemic. Soc Sci Med, 50(11), 1547-1556.

Backmund, M., Schuetz, C., Meyer, K., Edlin, B. R., \& Reimer, J. (2009). The risk of emergency room treatment due to overdose in injection drug users. J Addict Dis, 28(1), 68-73. doi:10.1080/10550880802545192

Bastos, F. I., \& Strathdee, S. A. (2000). Evaluating effectiveness of syringe exchange programmes: current issues and future prospects. Soc Sci Med, 51(12), 1771-1782.

Beletsky, L., Heller, D., Jenness, S. M., Neaigus, A., Gelpi-Acosta, C., \& Hagan, H. (2014). Syringe access, syringe sharing, and police encounters among people who inject drugs in New York City: A community-level perspective. International Journal of Drug Policy, 25(1), 105-111. doi:10.1016/j.drugpo.2013.06.005

Binswanger, I. A., Kral, A. H., Bluthenthal, R. N., Rybold, D. J., \& Edlin, B. R. (2000). High prevalence of abscesses and cellulitis among community-recruited injection drug users in San Francisco. Clin Infect Dis, 30(3), 579-581. doi:10.1086/313703

Birnbaum, H. G., White, A. G., Schiller, M., Waldman, T., Cleveland, J. M., \& Roland, C. L. (2011). Societal costs of prescription opioid abuse, dependence, and misuse in the United States. Pain Med, 12(4), 657-667. doi:10.1111/j.1526-4637.2011.01075.x

Blumenthal, D., Abrams, M., \& Nuzum, R. (2015). The Affordable Care Act at 5 Years. New England Journal of Medicine, 372(25), 2451-2458. doi:10.1056/Nejmhpr1503614

Briggs, D., Rhodes, T., Marks, D., Kimber, J., Holloway, G., \& Jones, S. (2009). Injecting drug use and unstable housing: Scope for structural interventions in harm reduction. DrugsEducation Prevention and Policy, 16(5), 436-450. doi:Pii 910577806

\subsection{0/09687630802697685}

Burris, S., \& Strathdee, S. A. (2006). To serve and protect? Toward a better relationship between drug control policy and public health. AIDS, 20(1), 117-118.

CDC. (2014). Viral Hepatitis Surveillance, 2014. Retrieved from

CDC. (2015a). CDC Health Advisory: Increases in Fentanyl Drug Confiscations and Fentanylrelated Overdose Fatalities. Retrieved from 
CDC. (2015b). Vital Signs: Today's Heroin Epidemic - More People at Risk, Multiple Drugs Abused. Retrieved from

CDC. (2016). Diagnoses of HIV infection in the United States and dependent areas, 2015. Retrieved from https://www.cdc.gov/hiv/statistics/overview/geographicdistribution.html

CDC. (2017). International Classification of Diseases, Tenth Revision, Clinical Modification (ICD-10-CM) [Press release]

CDC National Vital Statistics System, M. (2016). CDC WONDER. In: US Department of Health and Human Services.

Centers for Disease, C., \& Prevention. (2012). Integrated prevention services for HIV infection, viral hepatitis, sexually transmitted diseases, and tuberculosis for persons who use drugs illicitly: summary guidance from CDC and the U.S. Department of Health and Human Services. MMWR Recomm Rep, 61(RR-5), 1-40.

Chander, G., Himelhoch, S., \& Moore, R. D. (2006). Substance abuse and psychiatric disorders in HIV-positive patients: epidemiology and impact on antiretroviral therapy. Drugs, 66(6), 769-789.

Chitwood, D. D., McBride, D. C., French, M. T., \& Comerford, M. (1999). Health care need and utilization: A preliminary comparison of injection drug users, other illicit drug users, and nonusers. Substance Use \& Misuse, 34(4-5), 727-746. doi:Doi $10.3109 / 10826089909037240$

CMS. (2017). Medicaid \& CHIP in West Virginia. Retrieved from https://www.medicaid.gov/medicaid/by-state/stateprofile.html?state=west-virginia

Compton, W. M., Gfroerer, J., Conway, K. P., \& Finger, M. S. (2014). Unemployment and substance outcomes in the United States 2002-2010. Drug Alcohol Depend, 142, 350353. doi:10.1016/j.drugalcdep.2014.06.012

Conrad, C., Bradley, H. M., Broz, D., Buddha, S., Chapman, E. L., Galang, R. R., . . Duwve, J. M. (2015). Community Outbreak of HIV Infection Linked to Injection Drug Use of Oxymorphone - Indiana, 2015. MMWR Morb Mortal Wkly Rep, 64(16), 443-444.

Conrad, C., Bradley, H. M., Broz, D., Buddha, S., Chapman, E. L., Galang, R. R., .. . Prevention. (2015). Community Outbreak of HIV Infection Linked to Injection Drug Use of Oxymorphone--Indiana, 2015. MMWR Morb Mortal Wkly Rep, 64(16), 443-444.

Cooper, H. L., Linton, S., Kelley, M. E., Ross, Z., Wolfe, M. E., Chen, Y. T., . . National, H. I. V. B. S. S. G. (2016). Risk Environments, Race/Ethnicity, and HIV Status in a Large Sample of People Who Inject Drugs in the United States. PLoS One, 11(3), e0150410. doi:10.1371/journal.pone.0150410

Crime, U. N. O. o. D. a. (2016). World Drug Report 2016. Retrieved from United Nations Publication:

Des Jarlais, D. C., Nugent, A., Solberg, A., Feelemyer, J., Mermin, J., \& Holtzman, D. (2015). Syringe Service Programs for Persons Who Inject Drugs in Urban, Suburban, and Rural Areas - United States, 2013. MMWR Morb Mortal Wkly Rep, 64(48), 1337-1341. doi:10.15585/mmwr.mm6448a3

DHHR, W. (2017). HEALTH ADVISORY \#133 Increased Screening Recommendations for HIV Outbreak Detection Among Persons Who Inject Drugs. Retrieved from http://www.dhhr.wv.gov/oeps/disease/documents/hans/wv\%20hans/wv133-hivscreening-increased.pdf.

Dombrowski, K., Crawford, D., Khan, B., \& Tyler, K. (2016). Current Rural Drug Use in the US Midwest. J Drug Abuse, 2(3). 
Douthit, N., Kiv, S., Dwolatzky, T., \& Biswas, S. (2015). Exposing some important barriers to health care access in the rural USA. Public Health, 129(6), 611-620.

doi:10.1016/j.puhe.2015.04.001

Dufour, R., Joshi, A. V., Pasquale, M. K., Schaaf, D., Mardekian, J., Andrews, G. A., \& Patel, N. C. (2014). The prevalence of diagnosed opioid abuse in commercial and Medicare managed care populations. Pain Pract, 14(3), E106-115. doi:10.1111/papr.12148

Fairbairn, N., Milloy, M. J., Zhang, R., Lai, C., Grafstein, E., Kerr, T., \& Wood, E. (2012). Emergency Department Utilization among a Cohort of Hiv-Positive Injecting Drug Users in a Canadian Setting. Journal of Emergency Medicine, 43(2), 236-243. doi:10.1016/j.jemermed.2011.05.020

Farnham, P. G., Gopalappa, C., Sansom, S. L., Hutchinson, A. B., Brooks, J. T., Weidle, P. J., . . . Rimland, D. (2013). Updates of Lifetime Costs of Care and Quality-of-Life Estimates for HIV-Infected Persons in the United States: Late Versus Early Diagnosis and Entry Into Care. Jaids-Journal of Acquired Immune Deficiency Syndromes, 64(2), 183-189.

Fleischauer, A., Ruhl, L., Rhea, S., \& Barnes, E. (2017). Hospitalizations for Endocarditis and Associated Health Care Costs Among Persons with Diagnosed Drug Dependence North Carolina, 2010-2015. MMWR Morb Mortal Wkly Rep(66), 569-573. doi: http://dx.doi.org/10.15585/mmwr.mm6622a1

Fleishman, J. A., Monroe, A. K., Voss, C. C., Moore, R. D., \& Gebo, K. A. (2016). Expenditures for Persons Living With HIV Enrolled in Medicaid, 2006-2010. J Acquir Immune Defic Syndr, 72(4), 408-415. doi:10.1097/QAI.0000000000000985

Foundation, K. F. (2015). Health Insurance Coverage of the Total Population.

Foundation, K. F. (2017). Medicaid State Fact Sheets. Retrieved from http://www.kff.org/interactive/medicaid-state-fact-sheets/

French, M. T., McGeary, K. A., Chitwood, D. D., \& McCoy, C. B. (2000). Chronic illicit drug use, health services utilization and the cost of medical care. Social Science \& Medicine, 50(12), 1703-1713. doi:Doi 10.1016/S0277-9536(99)00411-6

Friedland, G. (2010). Infectious disease comorbidities adversely affecting substance users with HIV: hepatitis C and tuberculosis. J Acquir Immune Defic Syndr, 55 Suppl 1, S37-42. doi:10.1097/QAI.0b013e3181f9c0b6

Friedman, S. R., Pouget, E. R., Chatterjee, S., Cleland, C. M., Tempalski, B., Brady, J. E., \& Cooper, H. L. (2011). Drug arrests and injection drug deterrence. Am J Public Health, 101(2), 344-349. doi:10.2105/AJPH.2010.191759

Garfein, R. S., Vlahov, D., Galai, N., Doherty, M. C., \& Nelson, K. E. (1996). Viral infections in short-term injection drug users: the prevalence of the hepatitis $\mathrm{C}$, hepatitis $\mathrm{B}$, human immunodeficiency, and human T-lymphotropic viruses. Am J Public Health, 86(5), 655661.

Gebo, K. A., Keruly, J., \& Moore, R. D. (2003). Association of social stress, illicit drug use, and health beliefs with nonadherence to antiretroviral therapy. J Gen Intern Med, 18(2), 104111.

Gfroerer, J. C., Larson, S. L., \& Colliver, J. D. (2007). Drug use patterns and trends in rural communities. Journal of Rural Health, 23, 10-15. doi:DOI 10.1111/j.17480361.2007.00118.x

Grebely, J., \& Dore, G. J. (2014). Can hepatitis C virus infection be eradicated in people who inject drugs? Antiviral Res, 104, 62-72. doi:10.1016/j.antiviral.2014.01.002 
Harris, A. M., Iqbal, K., Schillie, S., Britton, J., Kainer, M. A., Tressler, S., \& Vellozzi, C. (2016). Increases in Acute Hepatitis B Virus Infections - Kentucky, Tennessee, and West Virginia, 2006-2013. MMWR Morb Mortal Wkly Rep, 65(3), 47-50. doi:10.15585/mmwr.mm6503a2

Holtzman, D., Barry, V., Ouellet, L. J., Jarlais, D. C. D., Vlahov, D., Golub, E. T., .. . Garfein, R. S. (2009). The influence of needle exchange programs on injection risk behaviors and infection with hepatitis $\mathrm{C}$ virus among young injection drug users in select cities in the United States, 1994-2004. Prev Med, 49(1), 68-73. doi:10.1016/j.ypmed.2009.04.014

Huo, D. Z., \& Ouellet, L. J. (2007). Needle exchange and injection-related risk behaviors in Chicago - A longitudinal study. Jaids-Journal of Acquired Immune Deficiency Syndromes, 45(1), 108-114. doi:Doi 10.1097/Qai.0b013e318050d260

Hurley, S. F., Jolley, D. J., \& Kaldor, J. M. (1997). Effectiveness of needle-exchange programmes for prevention of HIV infection. Lancet, 349(9068), 1797-1800. doi:10.1016/S0140-6736(96)11380-5

Jarlais, D. C., Perlis, T., Arasteh, K., Torian, L. V., Beatrice, S., Milliken, J., . . Friedman, S. R. (2005). HIV incidence among injection drug users in New York City, 1990 to 2002: Use of serologic test algorithm to assess expansion of HIV prevention services. American Journal of Public Health, 95(8), 1439-1444. doi:10.2105/Ajph.2003.036517

Jones, C. M., Logan, J., Gladden, R. M., \& Bohm, M. K. (2015). Vital Signs: Demographic and Substance Use Trends Among Heroin Users - United States, 2002-2013. MMWR Morb Mortal Wkly Rep, 64(26), 719-725.

Jones, G., Taright, N., Boelle, P. Y., Marty, J., Lalande, V., Eckert, C., \& Barbut, F. (2012). Accuracy of ICD-10 codes for surveillance of Clostridium difficile infections, France. Emerg Infect Dis, 18(6), 979-981. doi:10.3201/eid1806.111188

Kidorf, M., Disney, E. R., King, V. L., Neufeld, K., Beilenson, P. L., \& Brooner, R. K. (2004). Prevalence of psychiatric and substance use disorders in opioid abusers in a community syringe exchange program. Drug Alcohol Depend, 74(2), 115-122. doi:10.1016/j.drugalcdep.2003.11.014

Kidorf, M., King, V. L., Peirce, J., Burke, C., Kolodner, K., \& Brooner, R. K. (2010). Psychiatric distress, risk behavior, and treatment enrollment among syringe exchange participants. Addict Behav, 35(5), 499-503. doi:10.1016/j.addbeh.2009.12.033

Knowlton, A. R., Hoover, D. R., Chung, S. E., Celentano, D. D., Vlahov, D., \& Latkin, C. A. (2001). Access to medical care and service utilization among injection drug users with HIV/AIDS. Drug Alcohol Depend, 64(1), 55-62.

Ksobiech, K. (2004). Return Rates for Needle Exchange Programs: A Common Criticism Answered. Harm Reduct J, 1(1), 2. doi:10.1186/1477-7517-1-2

Kwon, J. A., Iversen, J., Maher, L., Law, M. G., \& Wilson, D. P. (2009). The impact of needle and syringe programs on HIV and HCV transmissions in injecting drug users in Australia: a model-based analysis. J Acquir Immune Defic Syndr, 51(4), 462-469. doi:10.1097/QAI.0b013e3181a2539a

Lee, T. A., Veenstra, D. L., Iloeje, U. H., \& Sullivan, S. D. (2004). Cost of chronic hepatitis B infection in the United States. J Clin Gastroenterol, 38(10 Suppl 3), S144-147.

Lin, W. C., Bharel, M., Zhang, J., O'Connell, E., \& Clark, R. E. (2015). Frequent Emergency Department Visits and Hospitalizations Among Homeless People With Medicaid: Implications for Medicaid Expansion. Am J Public Health, 105 Suppl 5, S716-722. doi:10.2105/AJPH.2015.302693 
Linton, S. L., Celentano, D. D., Kirk, G. D., \& Mehta, S. H. (2013). The longitudinal association between homelessness, injection drug use, and injection-related risk behavior among persons with a history of injection drug use in Baltimore, MD. Drug and Alcohol Dependence, 132(3), 457-465. doi:10.1016/j.drugalcdep.2013.03.009

Ly, K. N., Hughes, E. M., Jiles, R. B., \& Holmberg, S. D. (2016). Rising Mortality Associated With Hepatitis C Virus in the United States, 2003-2013. Clin Infect Dis, 62(10), 12871288. doi:10.1093/cid/ciw111

Mackesy-Amiti, M. E., Donenberg, G. R., \& Ouellet, L. J. (2012). Prevalence of psychiatric disorders among young injection drug users. Drug and Alcohol Dependence, 124(1-2), 70-78. doi:10.1016/j.drugalcdep.2011.12.012

Mackesy-Amiti, M. E., Donenberg, G. R., \& Ouellet, L. J. (2014). Psychiatric correlates of injection risk behavior among young people who inject drugs. Psychol Addict Behav, 28(4), 1089-1095. doi:10.1037/a0036390

Mackesy-Amiti, M. E., Finnegan, L., Ouellet, L. J., Golub, E. T., Hagan, H., Hudson, S. M., . . . Garfein, R. S. (2013). Peer-education intervention to reduce injection risk behaviors benefits high-risk young injection drug users: a latent transition analysis of the CIDUS 3/DUIT study. AIDS Behav, 17(6), 2075-2083. doi:10.1007/s10461-012-0373-0

McAdam-Marx, C., Roland, C. L., Cleveland, J., \& Oderda, G. M. (2010). Costs of opioid abuse and misuse determined from a Medicaid database. J Pain Palliat Care Pharmacother, 24(1), 5-18. doi:10.3109/15360280903544877

McCoy, C. B., Metsch, L. R., Chitwood, D. D., \& Miles, C. (2001). Drug use and barriers to use of health care services. Substance Use \& Misuse, 36(6-7), 789-806. doi:Doi 10.1081/Ja100104091

McKee, M. (2005). Understanding population health: lessons from the former Soviet Union. Clin Med (Lond), 5(4), 374-378.

Mizuno, Y., Purcell, D. W., Zhang, J., Knowlton, A. R., De Varona, M., Arnsten, J. H., \& Knight, K. R. (2009). Predictors of Current Housing Status Among HIV-Seropositive Injection Drug Users (IDUs): Results from a 1-Year Study. AIDS and Behavior, 13(1), 165-172. doi:10.1007/s10461-008-9364-6

Moss, R., \& Munt, B. (2003). Injection drug use and right sided endocarditis. Heart, 89(5), 577581.

Palepu, A., Tyndall, M. W., Leon, H., Muller, J., O'Shaughnessy, M. V., Schechter, M. T., \& Anis, A. H. (2001). Hospital utilization and costs in a cohort of injection drug users. CMAJ, 165(4), 415-420.

Paone, D., Jarlais, D. C. D., Caloir, S., Clark, J., \& Jose, B. (1995). Operational Issues in Syringe Exchanges - the New-York-City Tagging Alternative Study. Journal of Community Health, 20(2), 111-123. doi:Doi 10.1007/Bf02260333

Paulozzi, L. J. (2012). Prescription drug overdoses: a review. J Safety Res, 43(4), 283-289. doi:10.1016/j.jsr.2012.08.009

Peters, P. J., Pontones, P., Hoover, K. W., Patel, M. R., Galang, R. R., Shields, J., . . . Investigation, I. H. O. (2016). HIV Infection Linked to Injection Use of Oxymorphone in Indiana, 2014-2015. New England Journal of Medicine, 375(3), 229-239. doi:10.1056/Nejmoa1515195

Platt, L., Easterbrook, P., Gower, E., McDonald, B., Sabin, K., McGowan, C., . . Vickerman, P. (2016). Prevalence and burden of HCV co-infection in people living with HIV: a global 
systematic review and meta-analysis. Lancet Infect Dis, 16(7), 797-808.

doi:10.1016/S1473-3099(15)00485-5

Pollard, K., \& Jacobsen, L. (2017). The Appalachian Region: A Data Overview from the 2011 2015 American Community Survey Chartbook. Retrieved from https://www.arc.gov/assets/research_reports/DataOverviewfrom2011to2015ACS.pdf

Prisons, F. B. o. (2017). Inmate Offenses. Retrieved from https://www.bop.gov/about/statistics/statistics_inmate_offenses.jsp

Public Health and Welfare Act, (1988).

Regier, D. A., Farmer, M. E., Rae, D. S., Locke, B. Z., Keith, S. J., Judd, L. L., \& Goodwin, F. K. (1990). Comorbidity of mental disorders with alcohol and other drug abuse. Results from the Epidemiologic Catchment Area (ECA) Study. JAMA, 264(19), 2511-2518.

Rhodes, T., Singer, M., Bourgois, P., Friedman, S. R., \& Strathdee, S. A. (2005). The social structural production of HIV risk among injecting drug users. Soc Sci Med, 61(5), 10261044. doi:10.1016/j.socscimed.2004.12.024

Richardson, L., Wood, E., Li, K., \& Kerr, T. (2010). Factors associated with employment among a cohort of injection drug users. Drug and Alcohol Review, 29(3), 293-300. doi:10.1111/j.1465-3362.2009.00141.x

Rosenthal, E. S., \& Graham, C. S. (2016). Price and affordability of direct-acting antiviral regimens for hepatitis $\mathrm{C}$ virus in the United States. Infect Agent Cancer, 11, 24. doi:10.1186/s13027-016-0071-Z

Rudd, R. A., Aleshire, N., Zibbell, J. E., \& Gladden, R. M. (2016). Increases in Drug and Opioid Overdose Deaths - United States, 2000-2014. MMWR Morb Mortal Wkly Rep, 64(50-51), 1378-1382. doi:10.15585/mmwr.mm6450a3

Rudd, R. A., Seth, P., David, F., \& Scholl, L. (2016). Increases in Drug and Opioid-Involved Overdose Deaths - United States, 2010-2015. MMWR Morb Mortal Wkly Rep, 65(5051), 1445-1452. doi:10.15585/mmwr.mm655051e1

Sansone, R. A., Whitecar, P., \& Wiederman, M. W. (2009). The Prevalence of Childhood Trauma Among Those Seeking Buprenorphine Treatment. Journal of Addictive Diseases, 28(1), 64-67. doi:Pii 907640895

\section{$10.1080 / 10550880802545101$}

Shei, A., Rice, J. B., Kirson, N. Y., Bodnar, K., Enloe, C. J., Birnbaum, H. G., . . Ben-Joseph, R. (2015). Characteristics of High-Cost Patients Diagnosed with Opioid Abuse. J Manag Care Spec Pharm, 21(10), 902-912. doi:10.18553/jmcp.2015.21.10.902

Shepard, C. W., Finelli, L., \& Alter, M. J. (2005). Global epidemiology of hepatitis C virus infection. Lancet Infect Dis, 5(9), 558-567. doi:10.1016/S1473-3099(05)70216-4

Solomon, L., Frank, R., Vlahov, D., \& Astemborski, J. (1991). Utilization of Health-Services in a Cohort of Intravenous-Drug-Users with Known Hiv-1 Serostatus. American Journal of Public Health, 81(10), 1285-1290. doi:Doi 10.2105/Ajph.81.10.1285

Somaini, B., Wang, J., Perozo, M., Kuhn, F., Meili, D., Grob, P., \& Flepp, M. (2000). A continuing concern: HIV and hepatitis testing and prevalence among drug users in substitution programmes in Zurich, Switzerland. Aids Care-Psychological and SocioMedical Aspects of Aids/Hiv, 12(4), 449-460. doi:Doi 10.1080/09540120050123855

Spiller, M. W., Broz, D., Wejnert, C., Nerlander, L., Paz-Bailey, G., Centers for Disease, C., . . . National, H. I. V. B. S. S. S. G. (2015). HIV infection and HIV-associated behaviors among persons who inject drugs--20 cities, United States, 2012. MMWR Morb Mortal Wkly Rep, 64(10), 270-275. 
Statistics, U. S. B. o. L. (2017). West Virginia Economy at a Glance.

Suryaprasad, A. G., White, J. Z., Xu, F., Eichler, B. A., Hamilton, J., Patel, A., . . Holmberg, S. D. (2014). Emerging epidemic of hepatitis $C$ virus infections among young nonurban persons who inject drugs in the United States, 2006-2012. Clin Infect Dis, 59(10), 14111419. doi:10.1093/cid/ciu643

Takahashi, T. A., Baernstein, A., Binswanger, I., Bradley, K., \& Merrill, J. O. (2007). Predictors of hospitalization for injection drug users seeking care for soft tissue infections. J Gen Intern Med, 22(3), 382-388. doi:10.1007/s11606-006-0079-y

Takahashi, T. A., Maciejewski, M. L., \& Bradley, K. (2010). US hospitalizations and costs for illicit drug users with soft tissue infections. J Behav Health Serv Res, 37(4), 508-518. doi:10.1007/s11414-009-9177-z

Tookes, H., Diaz, C., Li, H., Khalid, R., \& Doblecki-Lewis, S. (2015). A Cost Analysis of Hospitalizations for Infections Related to Injection Drug Use at a County Safety-Net Hospital in Miami, Florida. PLoS One, 10(6), e0129360. doi:10.1371/journal.pone.0129360

United States Census Bureau: Statistical Abstract of the United States: 2011 (130th Edition). (2011, 2010). Retrieved from http://www.census.gov/statab/www/

Van Dorn, R. A., Desmarais, S. L., Young, M. S., Sellers, B. G., \& Swartz, M. S. (2012). Assessing illicit drug use among adults with schizophrenia. Psychiatry Res, 200(2-3), 228-236. doi:10.1016/j.psychres.2012.05.028

Van Handel, M. M., Rose, C. E., Hallisey, E. J., Kolling, J. L., Zibbell, J. E., Lewis, B., .. . Brooks, J. T. (2016). County-Level Vulnerability Assessment for Rapid Dissemination of HIV or HCV Infections Among Persons Who Inject Drugs, United States. J Acquir Immune Defic Syndr, 73(3), 323-331. doi:10.1097/QAI.0000000000001098

Vickerman, P., Kumaranayake, L., Balakireva, O., Guinness, L., Artyukh, O., Semikop, T., . . Watts, C. (2006). The cost-effectiveness of expanding harm reduction activities for injecting drug users in Odessa, Ukraine. Sex Transm Dis, 33(10 Suppl), S89-102. doi:10.1097/01.olq.0000221335.80508.fa

Warren, J., Gelb, A., Horowitz, J., \& Riordan, J. (2008). One in 100: Behind Bars in America in 2008. Retrieved from Washington D.C.:

White, A. G., Birnbaum, H. G., Mareva, M. N., Daher, M., Vallow, S., Schein, J., \& Katz, N. (2005). Direct costs of opioid abuse in an insured population in the United States. $J$ Manag Care Pharm, 11(6), 469-479. doi:10.18553/jmcp.2005.11.6.469

Wilson, D., Taaffe, J., Fraser-Hurt, N., \& Gorgens, M. (2014). The economics, financing and implementation of HIV treatment as prevention: what will it take to get there? Afr J AIDS Res, 13(2), 109-119. doi:10.2989/16085906.2014.943254

Wilson, D. P., Donald, B., Shattock, A. J., Wilson, D., \& Fraser-Hurt, N. (2015). The costeffectiveness of harm reduction. Int J Drug Policy, 26 Suppl 1, S5-11. doi:10.1016/j.drugpo.2014.11.007

Wodak, A., \& Cooney, A. (2005). Effectiveness of sterile needle and syringe programmes. International Journal of Drug Policy, 16, S31-S44. doi:10.1016/j.drugpo.2005.02.004

Yehia, B. R., Fleishman, J. A., Agwu, A. L., Metlay, J. P., Berry, S. A., Gebo, K. A., \& Network, H. I. V. R. (2014). Health insurance coverage for persons in HIV care, 2006-2012. J Acquir Immune Defic Syndr, 67(1), 102-106. doi:10.1097/QAI.0000000000000251 
Young, A. M., Havens, J. R., \& Leukefeld, C. G. (2012). A comparison of rural and urban nonmedical prescription opioid users' lifetime and recent drug use. Am J Drug Alcohol Abuse, 38(3), 220-227. doi:10.3109/00952990.2011.643971

Zibbell, J. E., Iqbal, K., Patel, R. C., Suryaprasad, A., Sanders, K. J., Moore-Moravian, L., . . . Holtzman, D. (2015). Increases in hepatitis C virus infection related to injection drug use among persons aged $</=30$ years - Kentucky, Tennessee, Virginia, and West Virginia, 2006-2012. MMWR Morb Mortal Wkly Rep, 64(17), 453-458.

Zibbell, J. E., Iqbal, K., Patel, R. C., Suryaprasad, A., Sanders, K. J., Moore-Moravian, L., . . Prevention. (2015). Increases in hepatitis $C$ virus infection related to injection drug use among persons aged $</=30$ years - Kentucky, Tennessee, Virginia, and West Virginia, 2006-2012. MMWR Morb Mortal Wkly Rep, 64(17), 453-458. 